8

LA-8778-MS

(i)

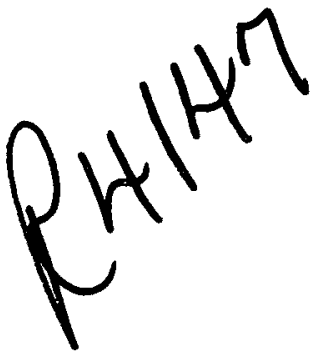

\section{Applications of Geothermal Well-Log Data for Evaluation of Reservoir Potential}




\section{DISCLAIMER}

This report was prepared as an account of work sponsored by an agency of the United States Government. Neither the United States Government nor any agency Thereof, nor any of their employees, makes any warranty, express or implied, or assumes any legal liability or responsibility for the accuracy, completeness, or usefulness of any information, apparatus, product, or process disclosed, or represents that its use would not infringe privately owned rights. Reference herein to any specific commercial product, process, or service by trade name, trademark, manufacturer, or otherwise does not necessarily constitute or imply its endorsement, recommendation, or favoring by the United States Government or any agency thereof. The views and opinions of authors expressed herein do not necessarily state or reflect those of the United States Government or any agency thereof. 


\section{DISCLAIMER}

Portions of this document may be illegible in electronic image products. Images are produced from the best available original document. 
An Affirmative Action/Equal Opportunity Employer

This report was not edited by the Technical Information staff.

DISCLAIMER

This report was prepared as an account of work sponsored by an agency of the United States Government. Neither the United States Government nor any agency thereof, nor any of their employees, makes any warranty, express or implied, or assumes any legal liability or responsibility for the accuracy, completeness, or usefulness of any information, apparatus, product, or process disclosed, or represents that its use would not infringe privately owned rights. Reference herein to any specific commercial product, process, or service by trade name, trademark, manufacturer, or otherwise, does not necessarily constitute or imply its endorsement, recommendation, or favoring by the United States Government or any agency thereof. The views and opinions of authors expressed herein do not necessarily state or reflect those of the United States Government or any agency thereof. 
LA-8778-MS

UC-66b

Issued: March 1981

\title{
Applications of Geothermal Well Log Data for Evaluation of Reservoir Potential
}

\author{
Prepared for \\ Los Alamos National Laboratory
}

by

F. A. Rigby*

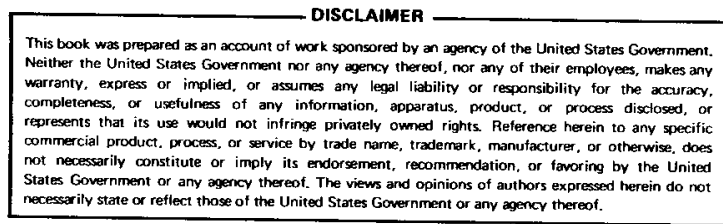

*Science Applications, Inc./Northwest, 13400-B Northrup Way, Suite 36, Bellevue, WA 98005.

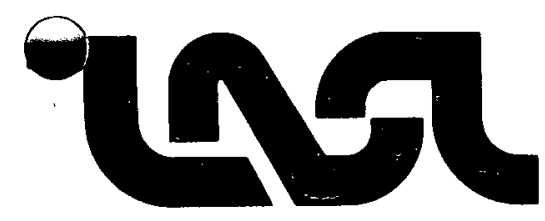


CONTENTS

ABSTRACT. . . . . . . . . . . . . . . . . 1

I. INTRODUCTION. . . . . . . . . . . . . . 2

II. SENSITIVITY OF WELL TEST BEHAVIOR TO WELL LOG

DERIVABLE PARAMETERS. . . . . . . . . . . . . . . . . . 5

A. Introduction. . . . . . . . . . . . . 5

B. Homogeneous, Single Porosity Reservoirs... . . . 6

C. Dual Porosity Reservoirs. . . . . . . . . . 8

D. Multi-Dimensional and Two-Phase Models. . . . . 30

E. Conclusions . . . . . . . . . . . . . 33

III. COMBINED INTERPRETATION OF WELL LOG DATA AND

SURFACE GEOPHYSICS. . . . . . . . . . . . . . . . 36

A. Introduction. . . . . . . . . . . . 36

B. East Mesa ................ . 40

C. Constrained Inversion Results . . . . . . . . 40

D. Vertical Extrapolation. . . . . . . . . . 51

E. Conclusions . . . . . . . . . . . . . 54

IV. BENEFITS ATTRIBUTABLE TO IMPROVED LOGGING DATA. • . . 55

A. Review of Benefit/Cost Analysis for Research in

Geothermal Log Interpretation . . . . . . . 55

B. Impact on Data Priorities . . . . . . . . . 63

C. Conclusions ............... 66

REFERENCES ................... . 68 


\section{APPLICATIONS OF GEOTHERMAL WELL LOG DATA}

FOR EVALUATION OF RESERVOIR POTENTIAL

by

F.A. Rigby

\section{ABSTRACT}

The process of geothermal well $\log$ interpretation must consider the application of the logging data as well as simply the manipulation of the logging tools' output. Improved data from geothermal logging can produce benefits by providing information that can be used to select better or less expensive choices in the drilling and completion and by providing more accurate reservoir data for resource evaluation and well siting. While geothermal well logging has many aspects in common with more conventional log interpretation techniques for hydrocarbon exploration, there are properties and problems characteristic of geothermal reservoirs that should be addressed as part of the development of geothermal log interpretation techniques. A great many geothermal reservoirs are naturally fractured systems with porosity supplied by both the macroscopic fracture system and by dispersed intergranular or vuggy porosity. This report discusses flow properties, the use of $10 \mathrm{~g}$ data for we 11 test interpretation in such systems, and the $\log$ derivable parameters that may be of most value for evaluation. Parameters for describing behavior of two-phase geothermal systems are also mentioned. Determination of reservoir dimensions is another important problem aggravated in geothermal resource evaluation by our limited knowledge of the geophysics of geothermal systems. The use of resistivity $10 \mathrm{~g}$ data to deduce constraints on the inversion of surface resistivity data is examined. Potentially valuable applications of resistivity $\log$ data in deducing reservoir dimensions and reaching decisions on exploratory drilling are indicated. 


\section{INTRODUCTION}

The use of well logging is a well-established part of the search for oil and natural gas. Years of experience in many areas of the world, combined with some degree of understanding of the geologic processes that affect the development of oil and gas reservoirs, have led to the development of well-defined and valuable applications of $\log$ data and to the development of effective techniques for obtaining these data. The range of experience available with geothermal resources on the other hand is still tiny in comparison to that which we have for oil and gas. Geothermal resources pose new problems for the log analyst. Techniques of interpreting well logging results to obtain the maximum amount of valuable information for geothermal resource evaluation are only now beginning to be developed.

It has been shown that the potential national benefits from a program of research in improved techniques for interpretation of geothermal well logs run at a minimum into the hundreds of millions of dollars over the next decade, and may be much greater if all actual benefits could be accurately quantified. ${ }^{1}$ Benefits were estimated to result from several factors, including reduced reinjection problems, earlier development due to increased certainty of resource evaluation, reduced costs associated with longterm flow testing, and improved drilling success resulting from factors such as better well siting. The applications of logging data that can lead to several of these benefits are fairly clear, 
and can be inferred from the uses made of $10 \mathrm{~g}$ data in other resource recovery operations such as petroleum drilling. Certain of the benefit estimates, however, rest on applications of well log data that are not well-developed in conventional drilling practice, either because the techniques are still being developed or because they relate specifically to geothermal resources. Two such cases were the assumption that geothermal well log data could be combined with surface geophysical data to solve some of the problems of geothermal exploration and improve reservoir definition, and the assumption that geothermal flow test evaluation and reservoir modeling could achieve enhanced accuracy using data from improved logging and interpretation techniques. In order to provide additional validation for these assumptions and an indication of valuable directions for research in geothermal $10 \mathrm{~g}$ interpretation, the uses of $10 \mathrm{~g}$ data for well test evaluation and inversion of surface geophysics were investigated.

The original cost/benefit study gave sensitivity estimates for the dependence of reservoir performance on formation parameters for a simple reservoir composed of a uniform porous medium. Since many geothermal reservoirs are more complex than this model, important effects may not have been covered. Section II of this report extends the examination of reservoir behavior by examining a model of flow in a fractured porous medium. The effects of finite boundaries and parameters needed for two-phase models and assessment of thermodynamic performance are also considered. The use of $10 \mathrm{~g}$ data to facilitate flow test evaluation is given extensive attention 
as a good indicator of current needs for geothermal $10 \mathrm{~g}$ interpretation. Formation thickness and dominant permeability are the most important formation parameters after formation and reservoir temperature. In addition, it is found that for fractured media the capability to accurately determine the porosity of the fracture system (as opposed to the matrix porosity) may be valuable. Measurement of total porosity is also valuable, and matrix block size (related to fracture spacing) appears to enter into more than one aspect of reservoir performance. Thermal conductivity of the formation is a parameter needed in modeling two-phase reservoirs (a parameter that draws its importance uniquely from the concerns of geothermal development).

In Section III results are presented of an effort to test the value of using well $\operatorname{logs}$ as constraints in the inversion of surface geophysics. Magnetotelluric data from the East Mesa area in California were inverted using constraints drawn from the resistivity $\log$ of a nearby well. It was found that a better picture of the reservoir could be obtained with the combined inversion than was revealed by the well $\log$ and the MT sounding separately.

Section IV updates the original cost/benefit analysis by introducing corrections for recent changes in energy cost and inflation. The updated benefit totals are used to examine the significance of the data applications examined in Sections II and III in the context of overall geothermal $\log$ interpretation concerns. 
II. SENSITIVITY OF WELL TEST BEHAVIOR TO WELL LOG DERIVABLE PARAMETERS

A. Introduction

Reservoir parameters necessary for the evaluation of the economic and energy potential of a geothermal reservoir are obtained from several sources. Local geology and surface geophysical studies contribute some information that may be critical to understanding basic reservoir structure or to determining reservoir extent. Other data, however, are drawn from wells probing the subsurface. Flow and pressure tests in these we11s, we11 $10 \mathrm{gs,}$ and core and cuttings samples that reveal properties of the formation are the principal sources of such data.

Ultimately, the evaluation of a geothermal resource amounts to evaluation of what can be brought up out of the ground in a we11. Since well test results deal with the behavior of the well, they bear a clear and direct relation to the questions to be answered. There are, however, a multiplicity of reservoir parameters that control the performance of a well. Well $10 \mathrm{~g}$ data are commonly used to establish the values of certain of the reservoir parameters beforehand to allow greater exactness in the evaluation of well tests.

Rigby and Reardon ${ }^{1}$ present some basic sensitivity analysis of the equations of steady flow and total energy content in a reservoir. that are relevant to determining those formation parameters most important to obtain from well logs. In view of the importance of well test analysis and of the dynamics of well behavior on longterm resource exploitation, however, it is also reasonable to 
examine more complex models of well performance to see the importance of parameters whose influence may be time-dependent. B. Homogeneous, Single Porosity Reservoirs

In a simple reservoir with homogeneous properties and only one flow regime for the fluid (i.e., permeability of only a single type either by means of primary porosity or through secondary porosity, provided it is sufficiently distributed to be essentially homogeneous) flow is radial and can be described fairly easily. For a constant rate of flow and constant parameters, the pressure change at the wellbore can be described by

$$
\Delta P=\frac{Q v}{4 \pi k h} \ln \left(\frac{4 D t}{G r_{w}^{2}}\right),
$$

where $\Delta P=$ drawdown (pressure change) (atm),

$$
\begin{aligned}
& Q=\text { flow rate }\left(\mathrm{cm}^{3} / \mathrm{s}\right), \\
& v=\text { viscosity }(\mathrm{cp}), \\
& k=\text { permeability (darcies), } \\
& h=\text { formation thickness }(\mathrm{cm}), \\
& D=\text { diffusivity }\left(\mathrm{cm}^{2} / \mathrm{s}\right), \\
& G=\text { antilogarithm of Eulers constant, } G=1.78 \ldots, \\
& t=\text { time (sec), and } \\
& r_{w}=\text { wellbore radius }(\mathrm{cm}) .
\end{aligned}
$$

This formulation is convenient, since on a semilog plot of drawdown (or pressure) against log time the curve will appear as a straight line with the slope determined by $\mathrm{kh} / \mathrm{v}$. If a linear 
compression law can be used (this may depend either on the fluid or on the compressibility of the pores of the formation) and compressibility is small so that the rate of change of porosity and permeability can be neglected,

$$
\mathrm{D}=\frac{\mathrm{k}}{\mathrm{vCJ}}
$$

where we use $C$ for compressibility (in $\mathrm{atm}^{-1}$ ) and $J$ for porositv. We obviously cannot define an intercept of the drawdown at $t=0$ in terms of Eq. (1), since a semilog plot has no such intercept. This reflects the fact that Eq. (1) does not apply at very small times due to transients caused by the initiation of flow. However, at larger times the drawdown can be computed if porosity,thickness, and compressibility are known. If the reservoir is finite, the curve will depart from a straight line at some large time which can again be determined if the formation parameters are known. Identification of boundary effects (and distance from the well) is needed for evaluation of resource size. The importance of permeability and thickness is obvious. Porosity appears to be less significant in geothermal development than is the case in hydrocarbon development, since the geothermal energy (heat) is not stored solely in the pore fluid. It is also stored in the rock, and the total heat content will in general be drawn upon by circulation of water in the reservoir as a result of recharge, either natural or artificial (reinjection). 


\section{Dual Porosity Reservoirs}

Geothermal reservoirs frequently have more complex properties than the simple assumptions of Eq. (1) can embrace. One of the most common characteristics of geothermal reservoirs is fracturing. ${ }^{2}$ In many geothermal areas the volcanic genesis and mineralization, either hydrothermal alteration or deposition which can reduce permeability through the intergranular (primary) porosity, cause all or part of the permeability to be provided by fractures. If the matrix rock is not totally impermeable, then the effect of the matrix porosity as well as the fracture porosity must be considered. In such a context new reservoir parameters in addition to those traditionally sought by the $\log$ analyst affect the performance of the resource, and it is important to consider the significance of these parameters in developing procedures for geothermal $10 \mathrm{~g}$ interpretation.

A valuable approach to understanding the performance of naturally fractured reservoirs is presented by deSwaan. ${ }^{3}$ The individual fractures can generally be expected to provide a much higher permeability than the matrix rock. Thus, except when only a very few, widely-spaced fractures are present, it can be anticipated that the primary route for flow to the wellbore will be provided by the fracture system, while fluid in the matrix porosity will diffuse toward the fractures and feed the flow in the fracture system. Pressure adjustments will occur very rapidly in the fracture system, while pressure changes in the matrix will occur more slowly and will be driven by the pressure in the 
fractures. If the fracturing is random or is otherwise adequate to provide high permeability flow paths toward the wellbore from all directions, flow at very short times will be dominated by flow in the fractures only, and will approximate Eq. (1) with the appropriate parameters for the fracture system. At times longer than these, a period occurs when flow is affected by both the fracture properties and the rate at which the fluid can diffuse outward from the matrix blocks (the unfractured material between fractures). At very long times, a condition is achieved in which the flow is slowly varying in comparison to the time scale of flow in the finite matrix blocks, and the flow is again described by Eq. (1) with the permeability equal to that of the fracture system. The diffusivity in Eq. (1) at these long times, however, will depend on the total porosity since both classes of porosity are contributing to the flow. We refer here to bulk fracture porosity. In several formulations that have appeared in the literature, point fracture properties are used which result in the necessity to include a shape factor depending on the assumed configuration of the matrix blocks in the expression for diffusivity at long times. This shape factor is not needed when bulk porosity is used. Figure 1 shows an approximation for a dual porosity formation similar to that used by Warren and Root, ${ }^{4}$, with regularly spaced fracture planes dividing the rock matrix into blocks in the shape of regular parallelepipeds. Such a system can be used to approximate a natural system assumed to have isotropic fracture permeability. Other conceptualizations with different fracture distributions and differently shaped matrix blocks can also be used provided fracture flow paths exist in all directions. 


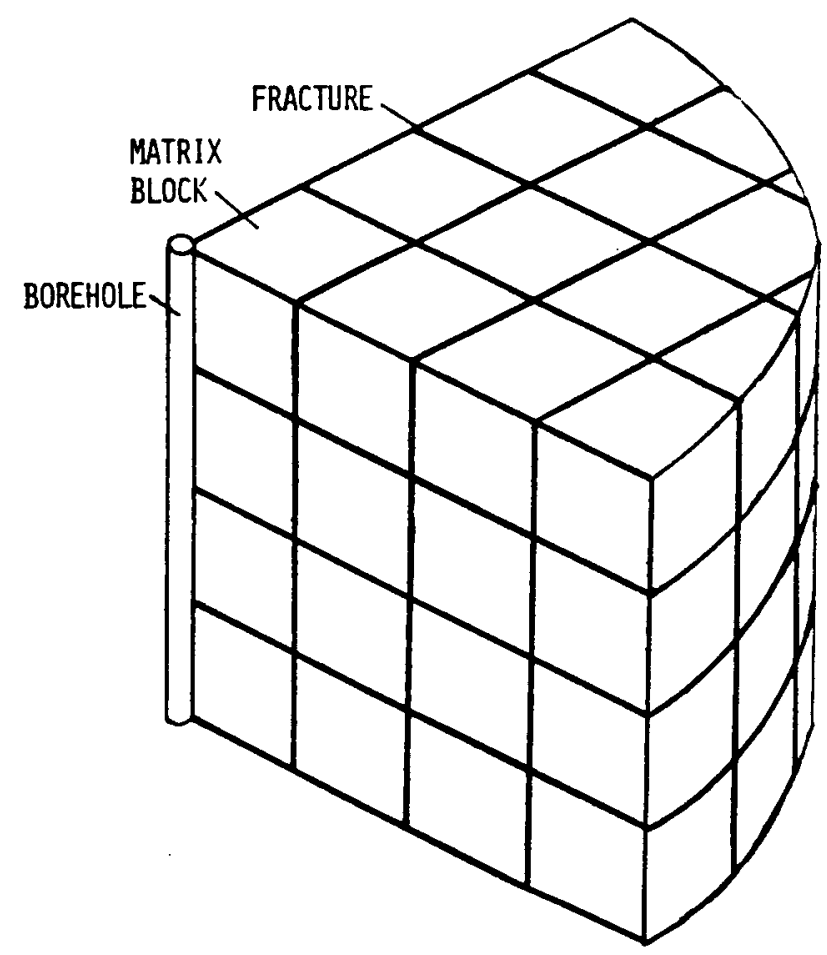

Fig. 1. Conceptualization of a possible approximation ${ }^{4}$ for a fractured medium with isotropic fracture permeability.

Intersecting fractures separate blocks of matrix material.

Although the discussion here is couched in terms of a system having fractures that provide relatively high permeability flow paths among matrix blocks having intergranular porosity and a $1 \mathrm{im}-$ ited degree of permeability, it should be kept in mind that the results described will also apply to other visualizations. For example, a system with scattered large fractures and a distributed "matrix" permeability and porosity resulting from small fractures and vuggy porosity would behave similarly. 
Various modeling studies ${ }^{4,5}$ support deSwaan's conclusions. The flow behavior and duration for the intermediate time period when the flow does not obey an equation of the form of Eq. (1) is controlled by (a) the apportionment of porosity between the fracture and matrix systems, (b) the permeabilities of the two systems, and (c) geometrical factors relating to the mean size of the matrix blocks.

Since these parameters may be important in geothermal reservoir evaluation and may be accessible through well log interpretation, a numerical model was used to investigate the significance of the above parameters. This model determined the behavior of a geothermal well for parameter values that are in the range that might be encountered in a geothermal well. Only single-phase flow of water (treated as nearly incompressible) was considered. While some geothermal resources have two-phase regions or may develop such regions under production, it seems clear that the great majority of geothermal resources are single-phase.

In the discussion presented here, attention will be given to the parameters that affect well test evaluation and to problems that may occur in evaluating fractured reservoirs. This, of course, implies determining which parameters have the greatest effect on well performance and thus which are of greatest importance in resource evaluation. The sensitivity of the flow in the formation to several of the parameters is found to be time-dependent. In some cases there is a significant sensitivity in some time interval and little or no effect at other times. To attempt to present 
numerical sensitivities that would only be good at a specific time and for a specific set of reservoix assumptions would be misleading. Instead, the discussion that follows is largely qualitative with examples shown by the figures to demonstrate the importance of various formation parameters.

1. Infinite Reservoirs. Table $I$ shows the set of parameters used as a base case. Flow rate is given assuming a 200 -meter thick formation. Figure 2 shows the drawdown curve for the values contained in Table $I$. In discussing the effect of changing parameter values for the fracture-matrix system, this format (drawdown at constant flow rate) will be used because it is convenient and the trend to a linear form at very short and very long times provides useful points of reference.

Since the model is based on a radial flow assumption, thickness simply enters linearly into the equations, and a change in the value of formation thickness is equivalent to a proportional change in flow rate. The importance of formation thickness as a $\log$ derived quantity in formation and well test evaluation is obvious and well-established, and is not changed by the consideration of dual-porosity in the reservoir.

\section{TABLE I}

BASE CASE FOR DUAL POROSITY MODEL

$\begin{array}{ll}\text { Fracture permeability } & =20 \mathrm{md} \\ \text { Initial pressure } & =200 \mathrm{~atm} \\ \text { Radius of matrix blocks } & =10 \mathrm{~m} \\ \text { Wellbore radius } & =10 \mathrm{~cm} \\ \text { Matrix porosity } & =5 \% \\ \text { Skin effect } & =0\end{array}$

$\overline{{ }^{\prime} \mathrm{md}}=$ millidarcies

$\begin{array}{ll}\text { Matrix permeability } & =0.5 \mathrm{md} \\ \text { Thickness } & =200 \mathrm{~m} \\ \text { Flow rate } & =2 \times 10^{4} \mathrm{~cm}^{3} / \mathrm{s} \\ \text { Reservoir area } & =5 \times 10^{6} \mathrm{~m}^{2} \\ \text { Fracture porosity } & =0.5 \% \\ \text { Compressibility } & =10^{-4} \mathrm{~atm}^{-1}\end{array}$

Matrix permeability $=0.5 \mathrm{md}$

Thickness

$=200 \mathrm{~m}$

$=2 \times 10 \mathrm{~cm}^{3} / \mathrm{s}$

$=0.5 \%$

$=10^{-4} \mathrm{~atm}^{-1}$ 


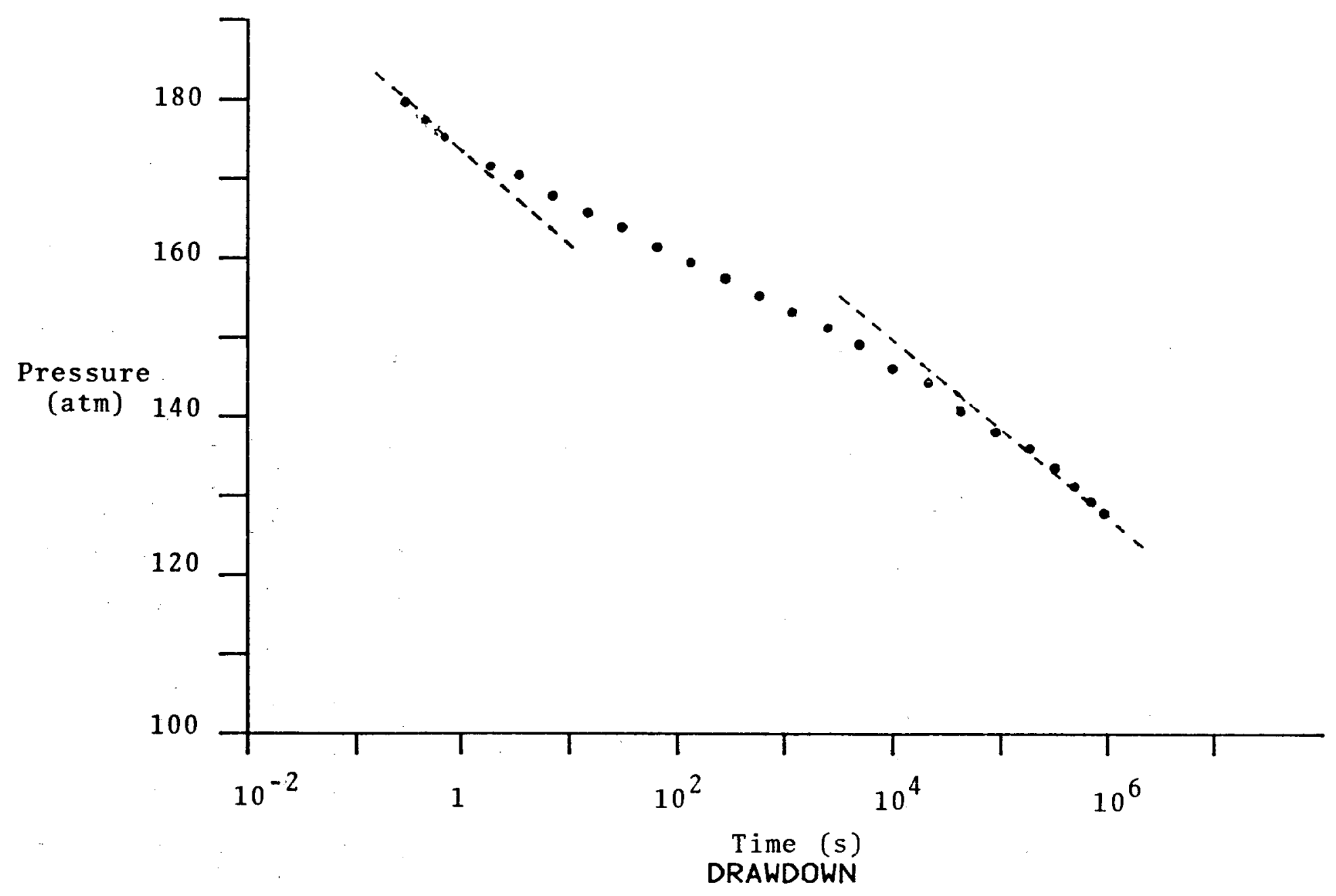

Fig. 2. Drawdown curve for the base case given in Table I. Dotted lines show the limiting slope at short and long times. 
Figure 3 shows the effect of varying fracture permeability. The differences in drawdown (change from initial pressure) at any given time are roughly linear with the change in fracture permeability. This is true not only in the long and short time limits of the curve, but also in the intermediate portion. Thus, there is little change in the importance of fracture permeability from that which it has in a single-porosity case.

Figure 4 displays curves showing the effect of varying matrix permeability. Matrix permeability was found to have very little effect on well performance. Reducing matrix permeability delays the time at which the curve departs from linear behavior and similarly retards the onset of linear behavior at long times, but the sensitivity is smaller than it is to some other parameters. Figure 5 shows curves for different matrix block sizes. The effect of matrix block size is similar to that of matrix permeability. However, the sensitivity to the block size would seem to be considerably greater. Although neither matrix permeability nor block size have a large impact on the overall drawdown curve, they can have a significant influence on the slope of certain portions of the curve (especially block size).

Figures 6 and 7 display the sensitivity to changing the fracture and matrix porosities. In Fig. 6 total porosity is the same for each curve, while the partition of the porosity between the matrix and the fractures is varied. The fact that long-term we11 performance is dependent on $1 y$ on total porosity 


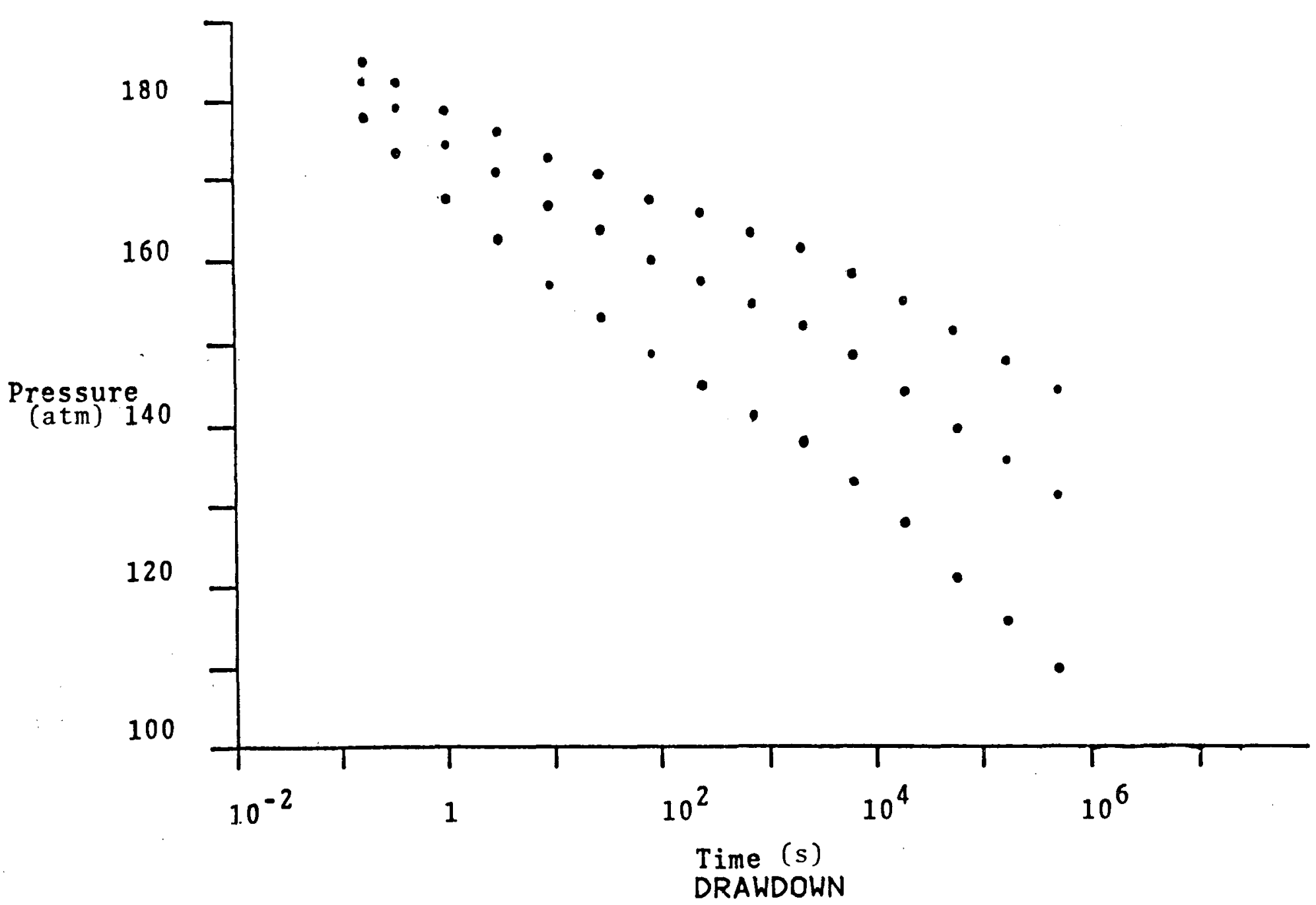

Fig. 3. Three curves showing the effect of different fracture permeabilities. The center curve is the base case $\left(k_{f}=20 \mathrm{md}\right)$. The upper curve has $k_{f}=25$ md (all other parameters

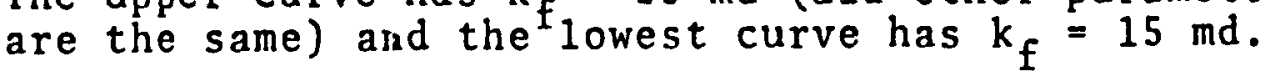




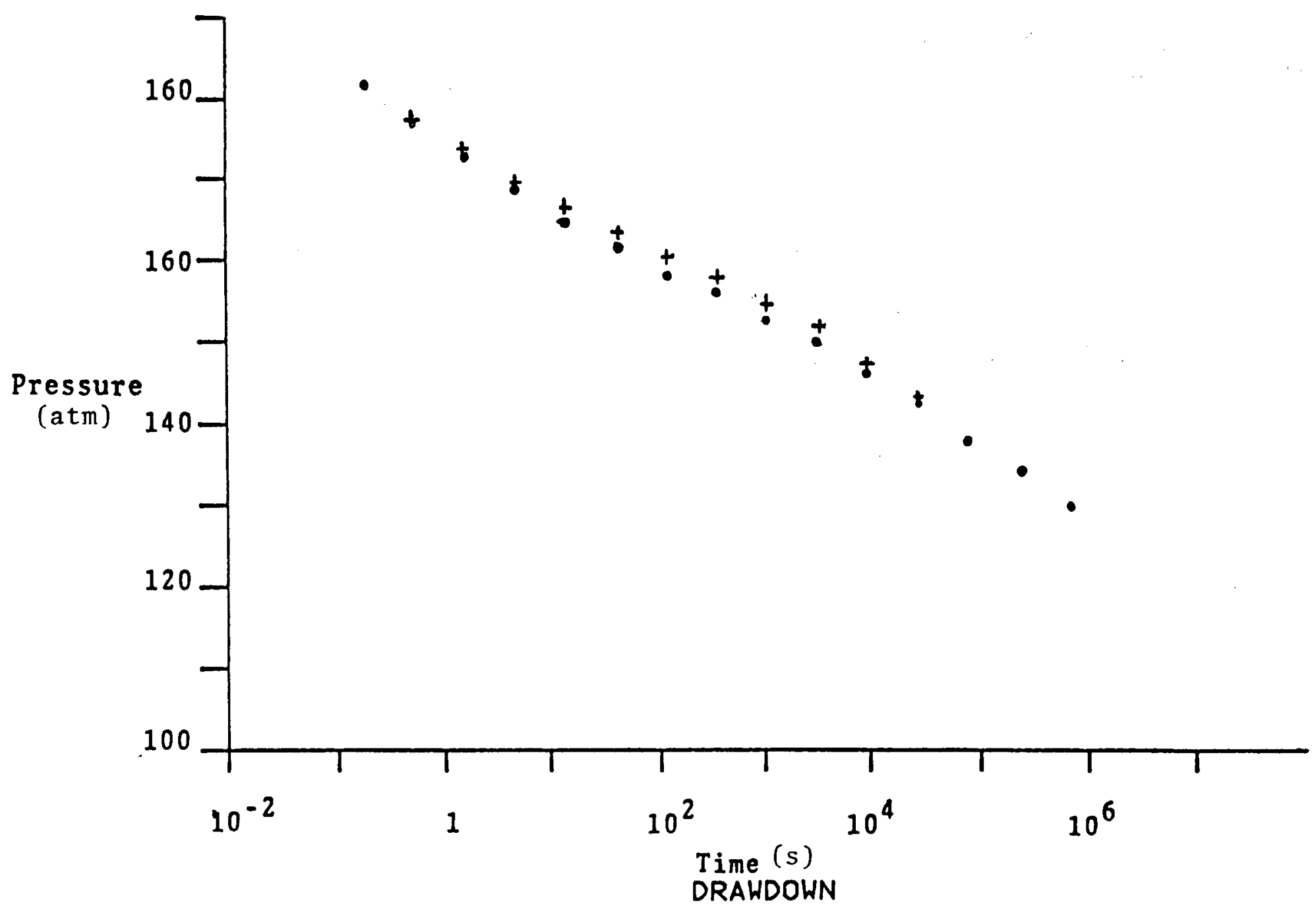

Fig. 4. Two curves showing the effect of matrix permeability. Parameters are the same as the base case except $(\cdot)$ represents $k_{m}=0.25 \mathrm{md}$ and $(+)$ where $k_{m}=1 \mathrm{md}$. The base case falls between the two. 


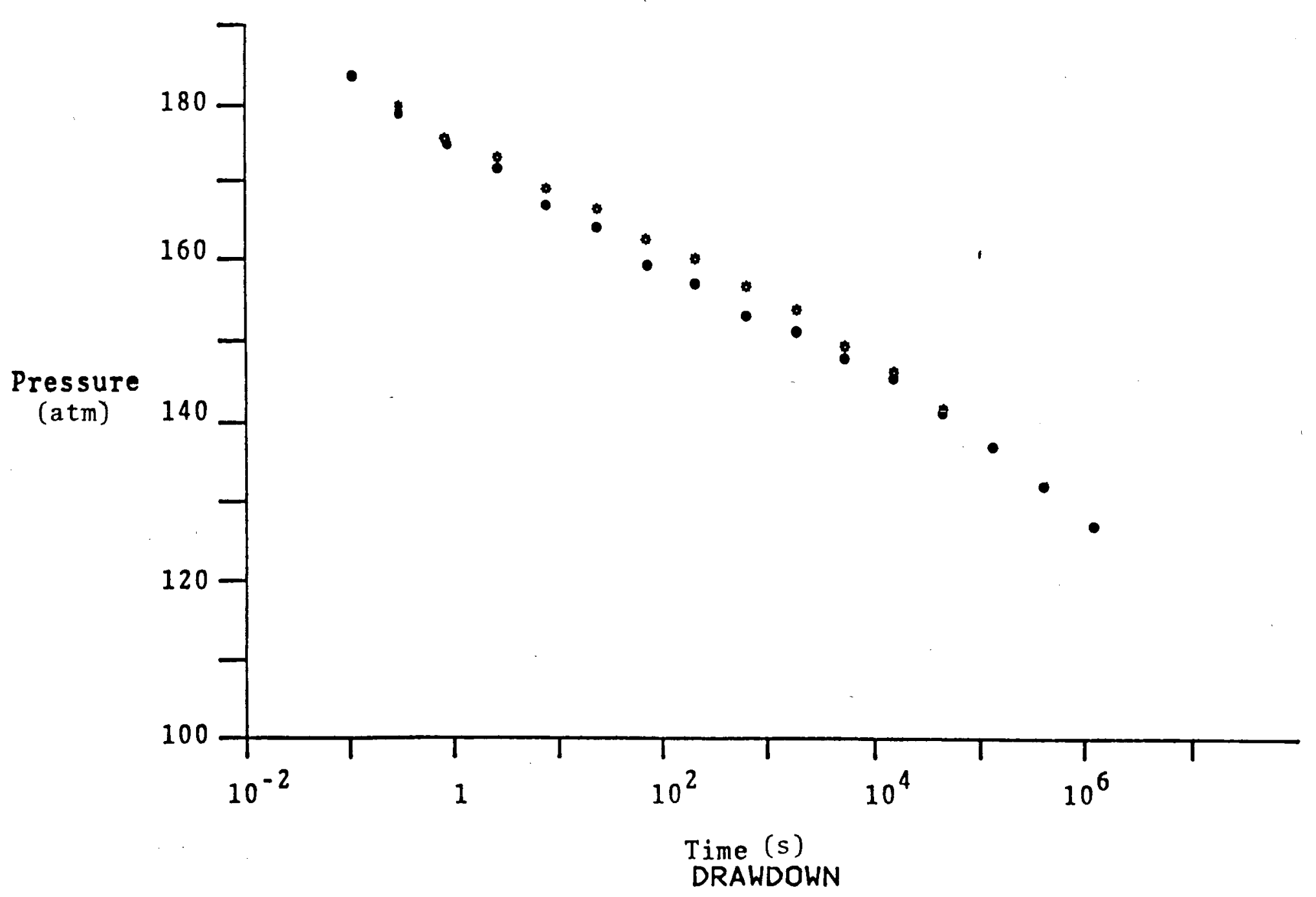

Fig. 5. Sensitivity to matrix block size $\left({ }^{\star}\right)$ represents a block radius of $5 \mathrm{~m},\left(_{0}\right)$ represents a block radius of $20 \mathrm{~m}$ (other parameters equal to the base case); the curve for the base case would fall between the two. 


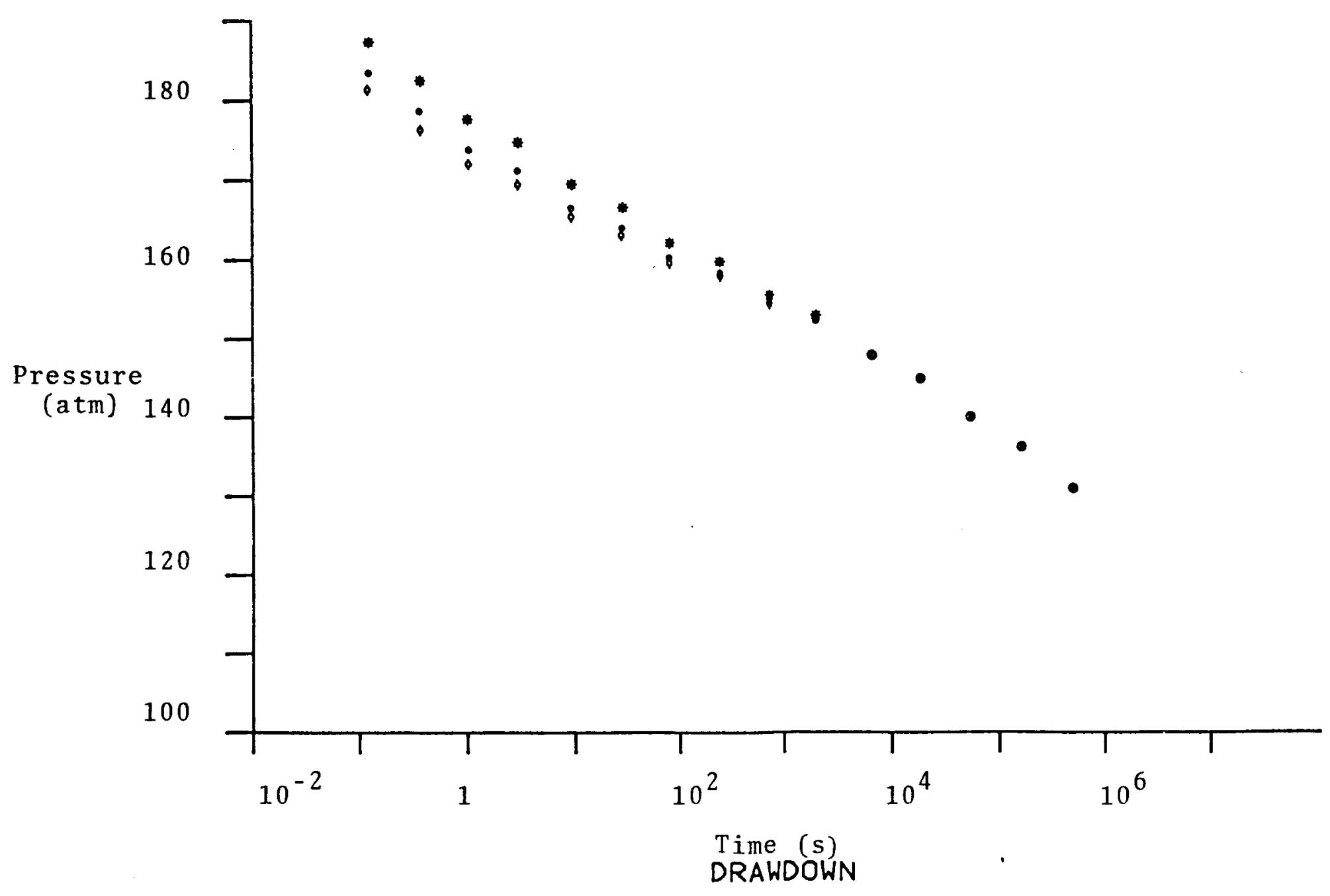

Fig. 6. Curves with varying fracture porosity, but the same total porosity. $(*)=1.5 \%,(\bullet)=0.5 \%$ (base case), and $(\phi)=0.25 \%$. Large dots indicate points at which the curves overlap. 
is clearly demonstrated. In Fig. 7 fracture porosity has been left unchanged while the matrix porosity is varied (and thus total porosity also varies). Thus, considering Figs. 6 and 7 together it is clear that at short times there is a considerable dependence on fracture porosity. At short times, matrix porosity has little effect, while even at long times the sensitivity to porosity is much less than the sensitivity to fracture permeability. 2. Implications for Reservoir Evaluation. The discussion of well behavior in dual porosity reservoirs presented in the previous section demonstrates that fracture permeability and formation thickness are the most important parameters in predicting the performance of fractured reservoirs with additional matrix porosity (intergranular or vuggy), as is the case in single porosity systems. However, additional parameters that also affect well performance have been noted. The sensitivity of well performance to the value of the matrix permeability is relatively small. Portions of the drawdown curve show somewhat greater sensitivity to changes in the matrix block size (fracture separation) at intermediate times. At short times there is significant sensitivity to the fracture porosity, while at long times only total porosity is important. If we now consider the data that could be sought from geothermal well logs for use in conjunction with well test results, it is clear that the permeability and reservoir extent (or connectedness when interference tests are considered) are the information that will be most particularly sought from the test data. 


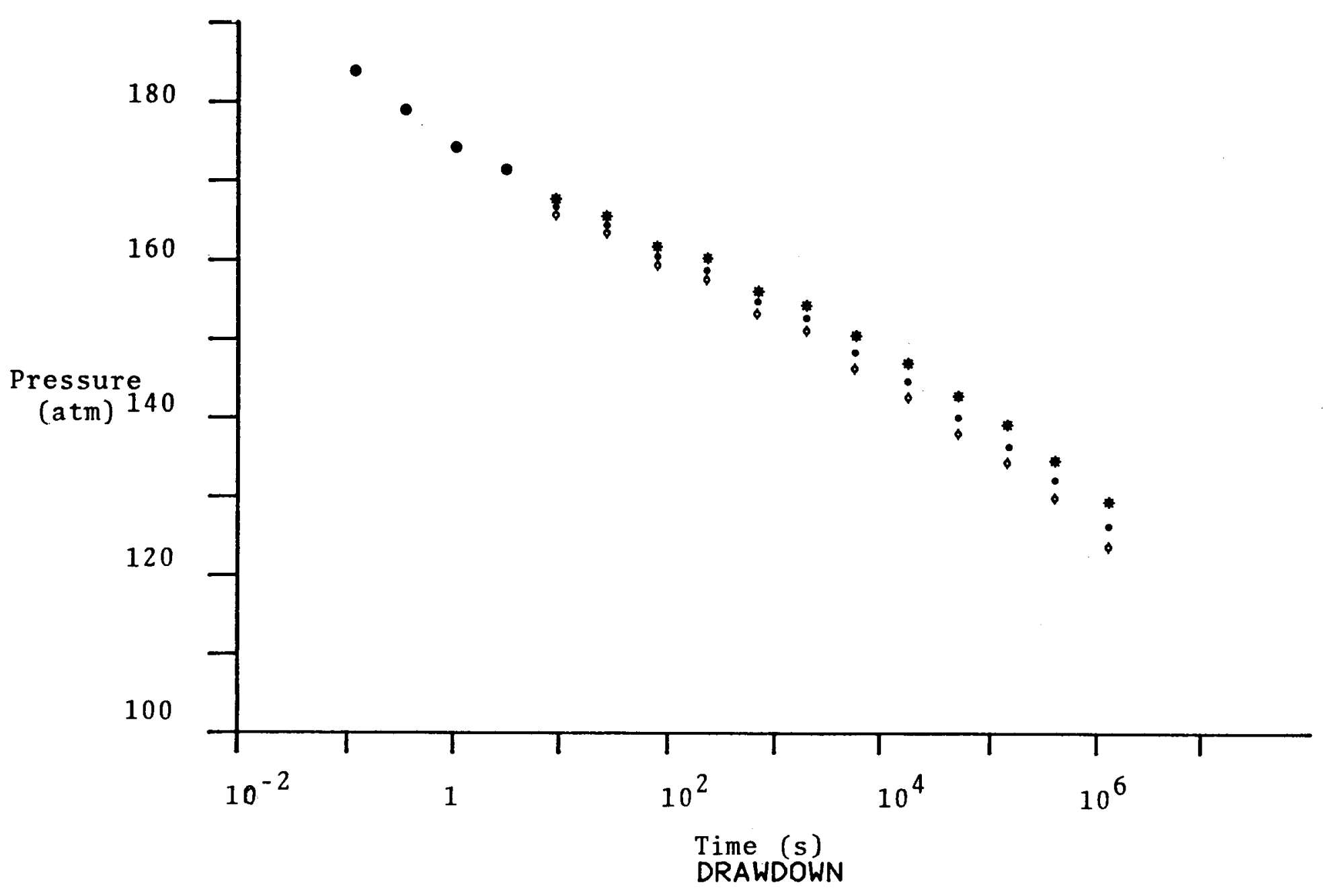

Fig. 7. Sensitivity to total porosity. Fracture porosity equals $0.5 \%$, matrix porosity differs, $(*)=10 \%$ $($ total porosity $=10.5 \%),(\bullet)=5 \%$ (base case), $(\phi)=2.5 \%$ (total porosity $=3 \%$ ). Large dots represent the portion of the three curves that are the same. 
These data are not easily obtained from other sources such as well logs, and are highly significant in the evaluation of longterm reservoir performance.

For an idealized reservoir such as has been discussed thus far, it is clear that the fracture permeability-thickness product could be determined from the slope of the approximately linear portions of the drawdown curve at the long and short time limits. However, for the short time end it seems unlikely that in a real data collection situation the flow will stabilize rapidly enough to allow sufficient data to be obtained over a period of at most a few seconds to satisfactorily define a slope for the curve. Although permeability can also be found from the slope at long times, it must be kept in mind that in a real reservoir some degree of inhomogeneity will probably be present that will tend to make it difficult to determine what portion of the drawdown eurve to use. Figure 8 shows the curve calculated for a matrix permeability of only 0.05 millidarcies with a matrix porosity of $2 \%$ and a $20-\mathrm{m}$ block radius (other formation parameters correspond to the base case shown in Fig. 2.). Given the low matrix permeability, it is tempting to suppose that the curve should approximate a single porosity case; and, indeed, even at times on the order of days $\left(t=10^{5} \mathrm{~s}\right)$ no break in the slope is obvious. The slope of the line shown on Fig. 8 approximating the curve from $t=5 \mathrm{~min}$ to $t=3$ days, however, gives a permeability of $k=27$ millidarcies (for viscosity of $1 \mathrm{cp}$ ) instead of the correct value of 20 millidarcies. The curve approaches the correct slope only for times on the order of weeks $\left(10^{6} \mathrm{sec}\right)$; and, as Fig. 8 shows, it is difficult to determine 


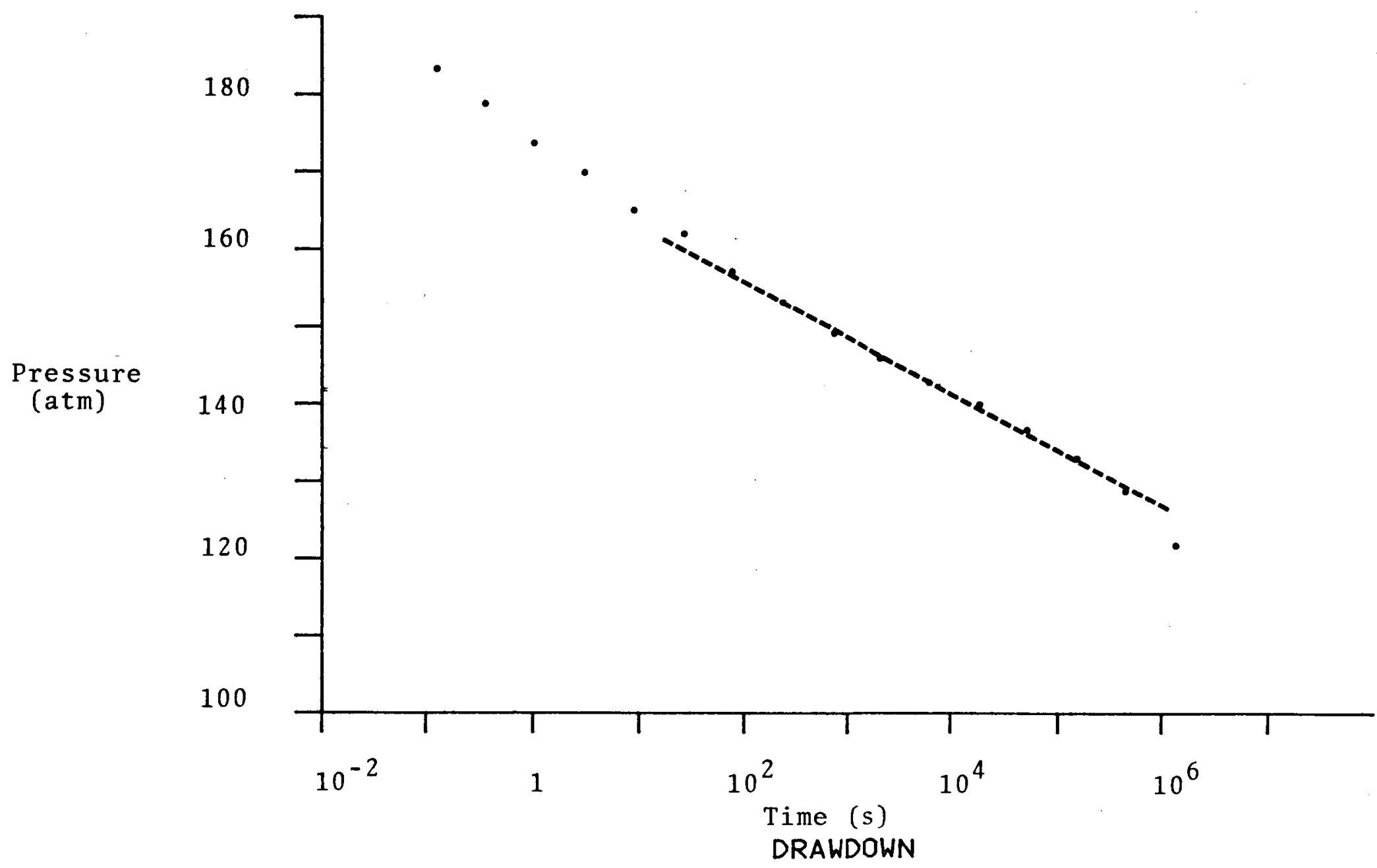

Fig. 8. Curve with matrix porosity $=2 \%$, block radius $=20 \mathrm{~m}$, matrix permeability $=0.05 \mathrm{md}$, other parameters as in a fracture permeability of $27 \mathrm{md}$ if the reservoir is treated as a single porosity system. 
from examination of the drawdown curve alone what portion of the curve to use.

We11 test durations on the scale of weeks represent significant costs, It is thus reasonable to suppose that there could be significant benefits gained if formation parameters obtained from logging data could be used to help estimate the required duration of flow testing. As the discussion in the preceding section shows, the matrix values for permeability, block size, and porosity are required for such an estimate, with the greatest sensitivity being to block size.

We have not discussed the influence of the fluid properties: viscosity and compressibility (compressibility may also be contributed to by the rock properties, producing compressibilities for the matrix pores and for the fractures). The effect of these parameters in the model used can be easily summarized. Viscosity (v) appears in the model only in connection with the permeability in the form $\mathrm{k} / \mathrm{v}$. Thus, the sensitivity to viscosity is the same as to the permeability but with opposite sign. Similarly, compressibility appears in the expression for the diffusivity along with porosity and has the same influence on the flow. The geometry of the matrix blocks also enters into the model in the form of a geometrical factor dependent on the relationship of surface area to volume. The model we have used assumes cylindrical matrix blocks. This shape was chosen as a reasonable approximation for matrix blocks in a formation in which fractures occur 
as predominantly vertical planes with varying azimuthal orientations. The significance of block geometry lies in the selection of an appropriate scale length for block size (e.g., thickness for flat slabs, twice the radius for cylinders, and $4 / 3$ the radius for spheres. This would seem to be a matter of secondary concern to the problem of determining any length scale for the matrix blocks.

The existence of finite limits on reservoir size also complicates the situation. This problem will be discussed in the next section.

3. Finite Reservoir Extent. Figure 9 shows curves for the same formation parameters as the base case (Table I) except that values of reservoir area of $5 \times 10^{5} \mathrm{~m}^{2}$ (radius of $1260 \mathrm{~m}$ ), $10^{6} \mathrm{~m}^{2}$ (radius of $564 \mathrm{~m}$ ), and $5 \times 10^{5} \mathrm{~m}^{2}$ (radius of $400 \mathrm{~m}$ ) are used. The effect of the boundary appears as a sudden dropping off of the drawdown curve. Since the model uses a one-dimensional radial flow assumption, limited extent is defined in terms of a limited radius--a $360^{\circ}$ boundary. In a real reservoir there would not be such uniform cutoff of the reservoir, and boundary effect might be less sharply defined.

If boundary effects are only felt in the long time limit of the drawdown curve, the time at which the boundary becomes significant depends only on thickness, fracture permeability, and total porosity.: However, Fig. 10 shows a case with a smaller 


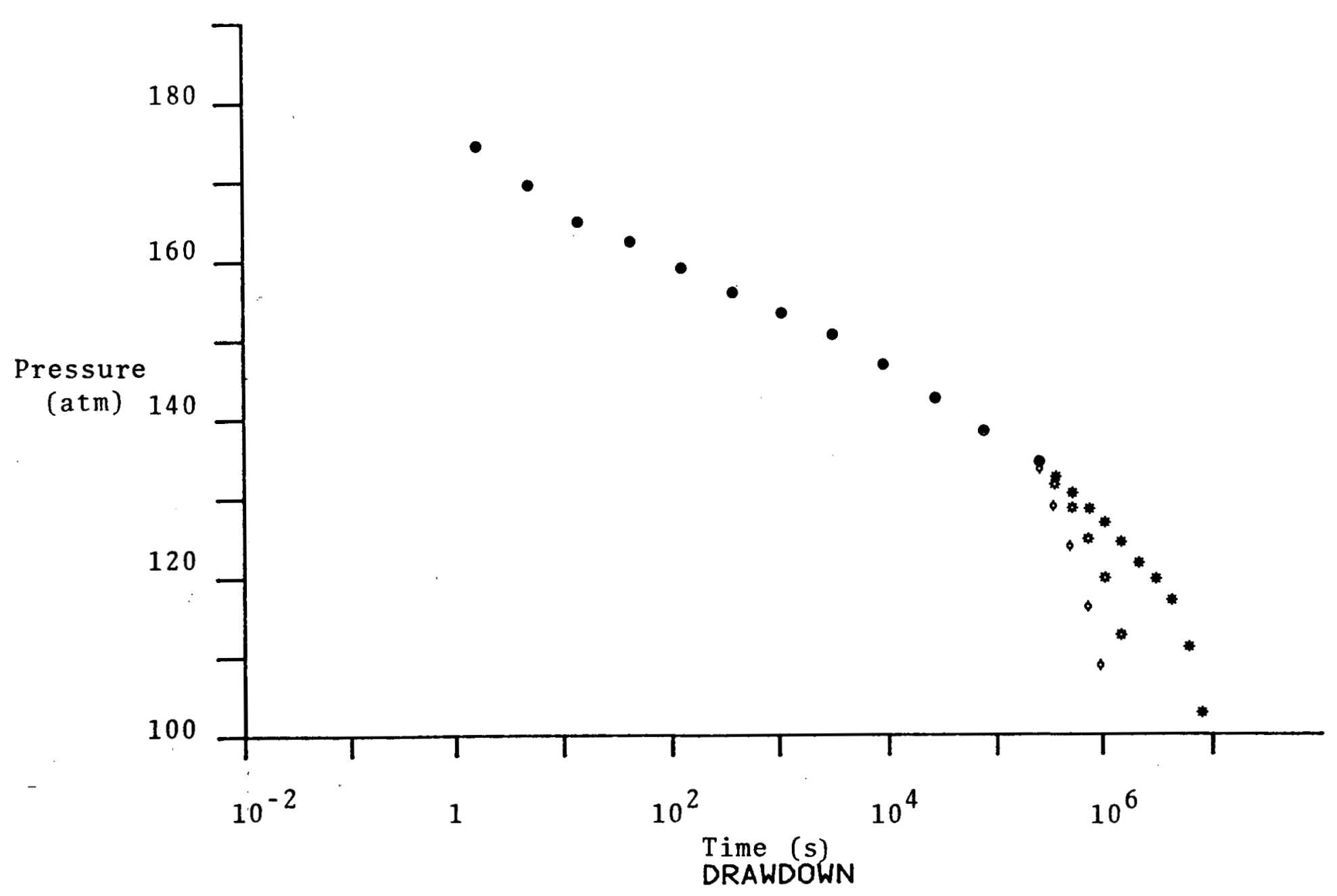

Fig. 9. Curves for the parameters of the base case but with

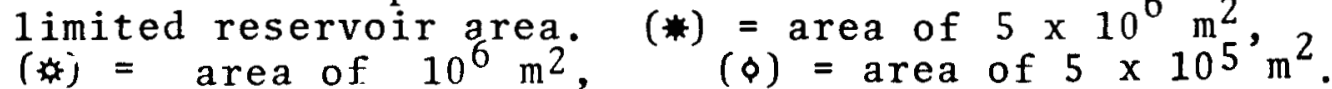
Large dots indicate the portion of the curves that are the same. 


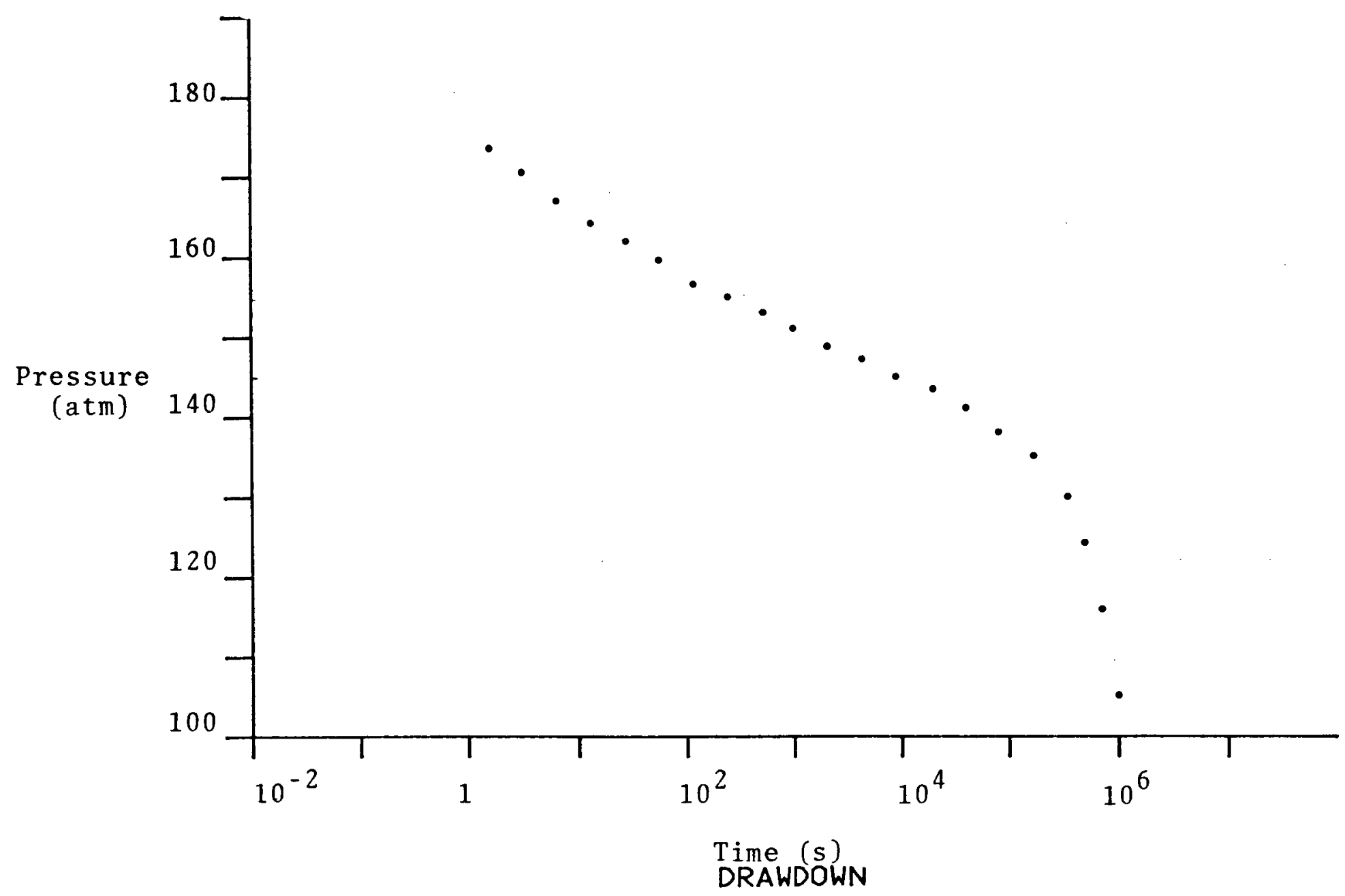

Fig. 10. Curve with $\mathrm{kf}_{\mathrm{f}}=20 \mathrm{md}, \mathrm{k}_{\mathrm{m}}=0.2 \mathrm{md}$, block radius $=20 \mathrm{~m}$, reservoir area of $5 \times 105 \mathrm{~m}^{2}$ (distance to boundary of $400 \mathrm{~m}$ ), and other parameters as in Table I (base case). The break in slope caused by the boundary effects is merged with the changing slope caused by dual-porosity effects, making it impossible to accurately identify specific features of the curve such as the onset of boundary effects. 
matrix permeability and larger fracture spacing (block size) for which the boundary effects become evident on a time scale that makes it imposssible to identify any portion of the curve as having clearly linear behavior at long times. This demonstrates the difficulty that may be encountered in determining fracture permeability from the slope at any point on the drawdown curve when the reservoir is finite and matrix block size is large or matrix permeability is small. At the same time the transition in slope from the well performance, affected by both fracture and matrix permeability to the long time case for which fracture permeability dominates, may be confused with the onset of boundary effects. Thus, the significance of the matrix properties will be increased when reservoirs of finite extent are considered.

It is worthwhile to consider what options exist for estimating fracture permeability when reliable slopes cannot be obtained at either the long or short time limits. If accurate porosity data are available, upper and lower bounds for fracture permeability can be obtained as described in the following paragraphs.

As was shown in Fig. 6, the values of drawdown at short times are controlled primarily by fracture permeability and porosity. Thus if a value for fracture porosity (and of course formation thickness) can be obtained from log data or other sources, the drawdown at the shortest time for which reliable values can be obtained can be substituted into Eq. (1) to compute an estimate 
of $k_{f}$. This will give an upper bound for the true value of $k_{f}$ as illustrated in Fig. 11 . Drawdown at $t=400 \mathrm{~s}$ is $45 \mathrm{~atm}$. Using $h=200 \mathrm{~m}, \mathrm{q}=20000 \mathrm{~cm}^{3} / \mathrm{s}, \mathrm{r}_{\mathrm{w}}=10 \mathrm{~cm}$, porosity $(\mathrm{J})=0.5 \%$, and compressibility $(\mathrm{C})=10^{-4} \mathrm{~atm}^{-1}, \mathrm{k}_{f}$ can be found from Eqs. (1) and (2) by a process of successive approximation. This gives $k_{f}=22 \mathrm{md}$, as opposed to the correct value of $20 \mathrm{md}$. Similarly, if a value is available for total porosity, a lower bound for $k_{f}$ can be computed from the drawdown at some point on the curve prior to the point at which boundary (lateral heterogeneity) effect distorts the curve. In Fig. 11 one might use $t=10^{4} \mathrm{~s}$ for which $\Delta \mathrm{P}=56 \mathrm{~atm}$. Then using these values together with total porosity $J=5.5 \%$ in Eqs. (1) and (2), we can obtain by successive approximation a value $\mathrm{k}_{\mathrm{f}} \approx 19 \mathrm{md}$. Such an approach would also be of value in the situation, not uncommon in geothermal exploratory drilling, in which the exploratory well can only be flowed to the limit of the capacity of the mud pit due to the lack of a reinjection well, thereby precluding long-term tests.

All the examples we have presented are calculated for an idealized, well-behaved reservoir for which quantities such as pressure and flow rate are assumed to be accurately measured. In a real geothermal well, the conditions of well testing are liable to be dictated as much by circumstances as by the desires of the analyst. The interpretation will be complex and may depend on numerical models; a fact which can only tend to increase the value of accurate values for formation properties. 


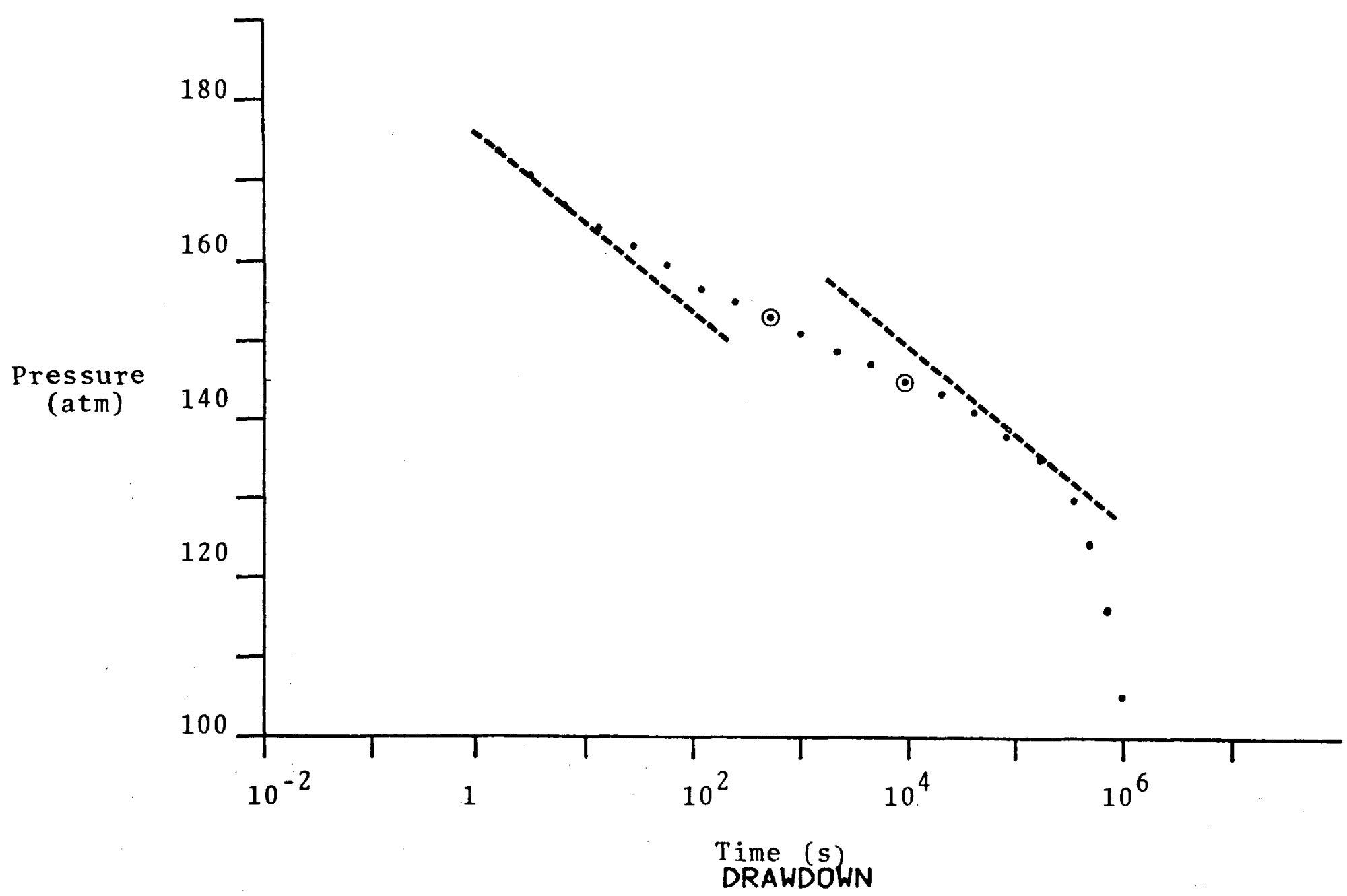

Fig. 11. Same curve as Fig. 10. The dashed lines show the slope defined by Eq. (1) for $k_{f}=20 \mathrm{md}$ and porosities of $0.5 \%$ (fracture porosity) and 2.5\% (total porosity). Drawdown values for points in the transition region, such as the circled points at $400 \mathrm{~s}$ and $10^{4} \mathrm{~s}$, are substituted into $\mathrm{Eq}$. (1). If the fracture porosity is used, the permeability bound wil1 be greater than $k$; if the total porosity is used, the permeability calculated will be less

than $k_{f}$. 


\section{Multi-Dimensional and Two-Phase Models}

Thus far this report has concentrated on the problems of fractured media using radial and single-phase assumptions. It has been shown that long-term well behavior in a fractured medium is controlled by fracture permeability, total porosity, and resource thickness and extent. It has also been noted that for long-term energy production under natural recharge or reinjection, the importance of porosity in determining available heat energy is reduced. For long-term reservoir evaluations, two- and threedimensional models exist that can take account of reservoir geometry. In addition, an area that has received a significant amount of research attention is the inclusion in such models of the capability of dealing with two-phase systems (water and steam), although in general it seems likely that the majority of geothermal reservoirs are single-phase.

In order to determine if there are additional parameters that are necessary to these models that have not been considered in the foregoing sections, the basic equations of several such models were examined. A recent review of reservoir simulators ${ }^{6}$ was found to be most helpful.

Many of the available models for large-scale reservoir simulations use simple porous medium assumptions and ignore dual porosity effects. These models therefore do not require several of the formation parameters which have been discussed. At least one model, however, does take account of fractures; and, for two-phase simulations, has indicated that there are significant differences 
from the results achieved with a single porosity assumption $(\operatorname{Ref}, 6)$.

The additional parameters that are called for in these models were found to be primarily associated with the problems of modeling two-phase behavior. The existence of both water and steam occupying the pore volume leads to the use of saturation of water $\left(S_{w}\right)$ and saturation of steam $\left(S_{S}\right)$ for the fractions of the total porosity filled by each fluid. In several models this also results in the use of irreducible water saturation as another formation parameter. Irreducible saturations are standard concepts in hydrocarbon reservoirs, and are often estimated from $\log$ data. In a singlephase geothermal reservoir the idea is meaningless, but when two phases are introduced the concepts of an irreducible water saturation $\left(\mathrm{S}_{\mathrm{WC}}\right)$ and critical stream saturation $\left(\mathrm{S}_{\mathrm{SC}}\right)$ again become reasonable. Unlike the case for hydrocarbon reservoirs the evaluation of irreducible saturations will not be easy in a two-phase geothermal reservoir. Not only would it be necessary to $10 \mathrm{~g}$ the well when it was at reservoir temperature, either the fortuitous occurrence or the intentional creation of fully-developed two-phase regions near the wellbore would be required.

As they appear explicitly in the equations, the role of the saturations are merely modifications on the porosity. However, $\mathrm{S}_{w c}$ and $\mathrm{S}_{\mathrm{SC}}$ also affect the relative permeabilities. Two-phase models must account for the relative permeability of the formation to steam and to water. These can be introduced by using some analytic expression derived from theory or empirical experience 
such as the formulas developed by Corey, et al. (Ref. 7), in which case $S_{W C}$ and $S_{S C}$ appear as parameters. Alternatively, the relative permeabilities as a function of steam and water content of the formation could be measured and introduced directly as input to the mode1. For this alternative it seems unlikely that log data could suffice; laboratory measurements using cores would be required.

The final formation parameters that need consideration are the thermal conductivity and heat capacity of the formation. In a two-phase reservoir these take on unique importance because of the heat transfers involved in phase transitions. These thermodynanic properties obviously have no role in the simple flow model used earlier in this report, but they should not be overlooked. Heat capacity is significant to the estimate of total heat in a reservoir, in addition to its impact on two-phase behavior. However, in terms of the range of variation among different rocks, it may be that an adequately accurate value for most requirements can be obtained by simply using a typical value based on the composition of the reservoir rather than attempting a direct estimate from logging results.

Thermal conductivity is affected by the structure of the rock, and the importance of obtaining it from log interpretation may deserve consideration. In addition to its significance in twophase behavior, the thermal conductivity may affect the temperature performance in a fractured system. When the reservoir is being produced and reinjection is done to "mine" heat from the formation, long-term temperature performance will depend on the rate of 
delivery of heat to the fracture surfaces. Reference 8 discusses this for hot dry rock systems.

E. Conclusions

For fractured media in which the fractures provide most of the permeability but the rock matrix is not totally impermeable, a greater number of parameters affect fluid flow than is the case for a simple porous medium.

Table II summarizes the importance of several parameters used to describe fractured media. The importance of determining formation thickness is unchanged; and, not surprisingly, permeability (in this case fracture permeability) remains of paramount importance. A variety of circumstances may complicate reservoir behavior and we11 test results. One datum that can be of use for interpretation is fracture porosity, which is not at present easily obtained from standard $10 \mathrm{~g}$ interpretations. Total porosity is also valuable information. The effective detection of both fracture and matrix porosity is needed to obtain total porosity. The problems of log response to fractures and the separation of fracture porosity from matrix porosity and from spurious effects (such as the influence of alternation products) is a challenging problem for geothermal log inter pretation. The traditional approach to log interpretation is to seek point quantities. That is, even though a logging tool averages over some volume, its output is interpretable as a point value representing some running average of formation properties. For something such as fracture porosity which is more highly discrete than most bulk formation characteristics, it may be that statistical features of the logs can be related to fracture porosity even in a situation where reliable fracture identification is not feasible. 
TABLE II

SENSITIVITY OF MODELED FRACTURED MEDIUM FLOW

\section{Parameter}

Formation

Thickness, H

Fracture

Permeability, $k_{f}$

Fracture

Porosity, $\phi_{f}$

Matrix Block Size

Matrix Porosity, $\phi_{m}$

Matrix

Permeability, $\mathrm{k}_{\mathrm{m}}$

Therma1

Characteristics
Sensitivity

Very High

Very High

Significant at Limited Duration

Medium

Medium

Low

Thermal conductivity and heat capacity of the matrix are called for in two-phase flow models

\section{Comments}

If formation is modeled as a uniform slab, flowrate is proportional to thickness.

$\mathrm{k}_{f}$ assumed to be substantially greater than matrix permeability $\left(k_{m}\right)$ (Fig. 3)

$\phi_{f}$ assumed to be less than matrix porosity $\phi_{m}$. If $\phi_{f}$ is a significant portion of total porosity, it also affects the drawdown at long times (Fig. 6)

Affects flow characteristics at intermediate times; large matrix blocks can influence flow on time scales as large as days or weeks (Figs. 5 and 8 )

Needed as part of total porosity (Fig. 7)

Fig. 4

Ref. 6 
Matrix block size was also determined to be of some importance. Although the sensitivity to block size was less than the sensitivity to various fracture properties, block size had significant impact compared to the matrix properties. Where identification of fracture location from log data is feasible, some information on block size can obviously be extracted, and this tends to add to the importance of fracture identification and location in geothermal log interpretation. Data on fracture orientations could add to the precision of such estimates. In wells in which fracture identification and location are a problem, it may again be worthwhile to ask if there are statistical comparisons that can be made of different logging data sets that will relate to matrix block size.

Thermal conductivity of the formation appears as a parameter in two-phase flow models. The potential for determining thermal conductivity from $\log$ data is not clear.*

\footnotetext{
* Although a temperature log of a static well will not provide an evaluation of thermal conductivity of the formation rocks, it does appear possible to use temperature surveys obtained during injection of cold water. See: J. N. A1bright, "A New and More Accurate Method for the Direct Measurement of Earth Temperature Gradients in Deep Boreholes," 2nd UN Symp. Devel. Geotherm. Res. (1976); H. D. Murphy, "Fluid Injection Profiles - a Modern Analys is of Wel1bore Temperature Surveys," 52nd An. Fal1 Tech. Conf. and Exhib. SPE of AIME (1977); J. G. Conaway, "Deconvolution of Temperature Gradient Logs," Geophys. 42 (1977), 823; M. J. Edwardson et a 1., "Calculation of Formation Temperature Disturbances Caused by Mud Circulation," J. Pet. Tech. (Apri1 1962), 416; W. L. Dowdle and W. M. Cobb, "Static Formation Temperature from Well Logs - An Empirical Method," J. Pet. Tech. (Nov. 1975), 1326; J. C. Jaeger, "The Use of Complete Temperature-Time Curves for Determination of Thermal Conductivity with Particular Reference to Rocks," Australian J. Phys. 12 (May 1959), 203; H. D. Murphy and R. G. Lawton, "Downhole Measurements of Thermal Conductivity in Geothermal Reservoirs," J. Pres. Ves. Tech. (Nov. 1977), 607; T. C. Urban et al., "East Mesa Geothermal Anomaly, Imperial County, California: Significance of Temperatures in a Deep Drill Hole near Thermal Equilibrium," Trans. Geotherm. Res. Council 2 (July 1978), 667.
} 
III. COMBINED INTERPRETATION OF WELL LOG DATA AND SURFACE GEOPHYSICS

A. Introduction

In the previous section we examined the requirements of geothermal and resource evaluation for data on various formation characteristics that may potentially be obtained from well 1 ogs. We included references to a recent review of geothermal reservoir modeling by Pinder (Ref. 6). In his conclusions Pinder includes an interesting figure which, he cautions the reader, is purely his subjective estimate of the sources of uncertainty in present reservoir simulation. Figure 12 reproduces this figure. Although the figure represents only one man's guess, it is nonetheless an informed guess by someone who has been reviewing the field; and while any other researcher reviewing the subject matter (including this author) would probably argue for specific modifications, the overall presentation is reasonable. Figure 12 indicates the greatest uncertainty in present reservoir simulations rests with the estimates available of formation characteristics, and the next most significant source of uncertainty lies in determining reservoir geometry, which presumably includes but is not limited to simple estimation of resource size. The previous section of this report has discussed some aspects of the use of logging data from geothermal wells to provide parameter estimates. This section will deal with an effort that was made to test one approach for using log data in defining reservoir dimensions. 


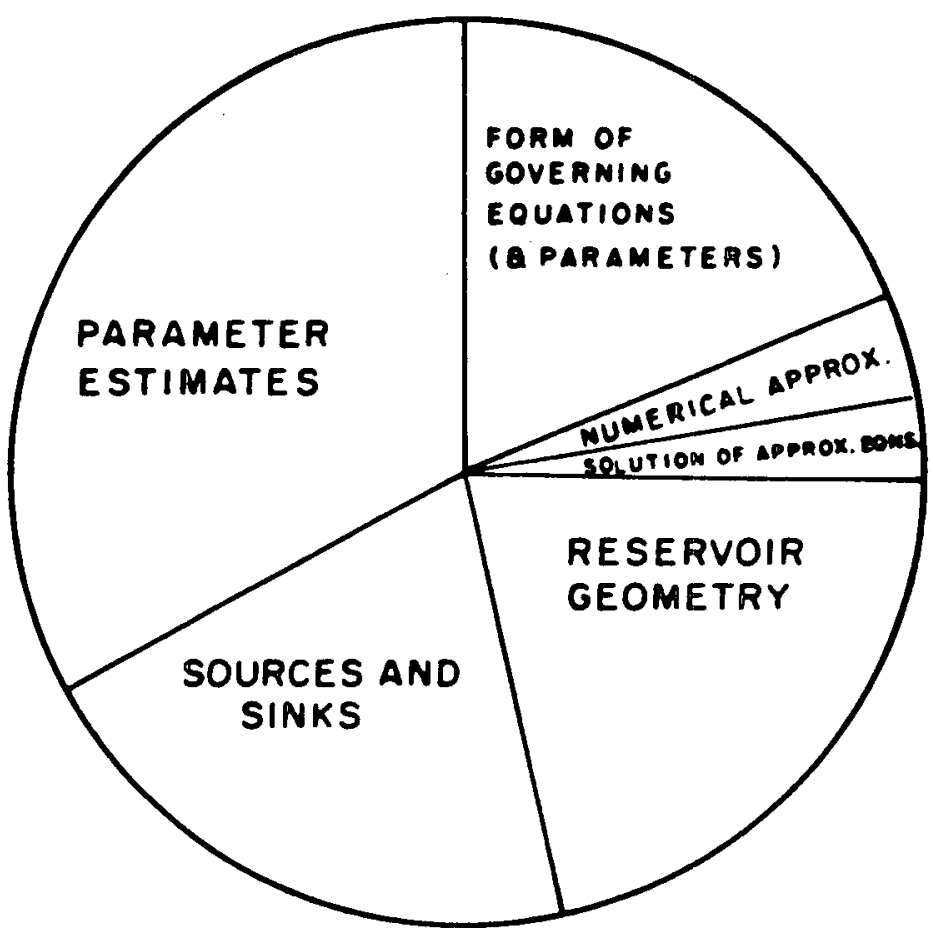

Fig. 12. Estimate of the uncertainty distribution among elements of geothermal reservoir simulation (from Ref. 6). 
Surface geophysical data can contribute to reservoir evaluation by locating reservoir boundaries and helping define reservoir geometry and inhomogeneity. Surface geophysics can achieve an areal coverage that a drilling program can on 1 y duplicate at great expense. However, the picture (model) of the subsurface that can be derived from surface data is never perfect. The degree of uncertainty depends on the accuracy and density of the measurements and the nature of the subsurface formations. Furthermore, even an accurate inversion of the surface data may be ambiguous in terms of resource evaluation if the relationship of reservoir features to the geophysical measurements is not clear (e.g., if the relationship of measurements such as seismic wave velocities to desirable features such as high temperature or permeability is not known).

If data from a well are combined with the surface geophysics, several possibilities for improved interpretation exist. Most simply, knowledge of the behavior of the well together with $10 \mathrm{~g}$ data from the well may identify producing intervals and make it possible to determine measurable quantities such as resistivity, magnetization, or acoustic properties, which are characteristic of the producing zones. In addition, the vertical data provided from the well can provide either initial conditions or constraints for the inversion of the surface geophysical data to improve the accuracy of the inversion. The possibility that useful borehole-tosurface or borehole-to-borehole data might be obtained from the well also exists but is outside the scope of the present study, which was limited to more conventional logging techniques. 
Combination of surface and borehole data has been investigated in the last few years in the oil and gas industry. Because of the high degree of development of seismic techniques for hydrocarbon exploration, most of the concentration has been on uses of seismic data. Valuable results have been obtained with the use of sonic and density $\log$ data in conjunction with seismic surveys (Ref. 9). However, when we deal with geothermal exploration, the value of seismic data as an exploration tool is often reduced because the geothermal resource is not necessarily related to structural features that are good seismic targets. In many geothermal areas emphasis has been placed on the use of measurements relating to electrical properties, since the hot and frequently saline fluids that carry geothermal energy can directly affect the electrical properties of the formation. Nonetheless, the interpretation of geothermal features based on resistivity data and other electrical measurements is often ambiguous, since rock properties as well as fluid properties may be responsible for the observed results (Ref. 10).

In order to investigate the potential value of combining $10 \mathrm{~g}$ data and surface data for geothermal areas, especially with respect to resistivity data, surface resistivity data and resistivity logs were examined for several geothermal areas to find a candidate for which inversion of the surface data using constraints drawn from the logs could be attempted. At most of the areas examined, it was found that the surface resistivity data were limited in quality and in depth of penetration. Deep resistivity soundings were 
generally not available nor were telluric or magnetotelluric data with sufficient frequency coverage to allow detailed inversions. One adequate data set was found, however, for the East Mesa geothermal field.

\section{B. East Mesa}

The East Mesa geothermal area is in the southeastern portion of California's Imperial Valley near the Mexican border (Fig.13). Geothermal fluids with temperatures of 150 to $170{ }^{\circ} \mathrm{C}$ are produced from a formation consisting of sandstones and shales. Faults through the area apparently provide conduits along which fluids circulate to depth and extract heat from basement rocks heated by magmatic intrusions. The first extraction of geothermal fluids was performed by the U.S. Bureau of Reclamation for desalination studies.

Three of the Bureau of Reclamation's wells, Mesa 6-1, 6-2, and $8-1$, form a compact triangle covering a few square kilometers in a reasonab1y productive area of the formation. Figure 14 shows the location of these wells and the relationship to other wells in the area. Surface data for a point close to the location shown for Mesa 6-1 were obtained from an unpublished magnetotelluric sounding curve made for the Bureau of Reclamation (Ref. 11). This curve was made using a cryogenic magnetometer and remote reference techniques and provided good accuracy and detail. Figure 15 displays the sounding curve used. C. Constrained Inversion Results

A computer code for the inversion of resistivity data, CRIMPA (Complete Resistivity Inversion and Modeling: Package--Automated) 


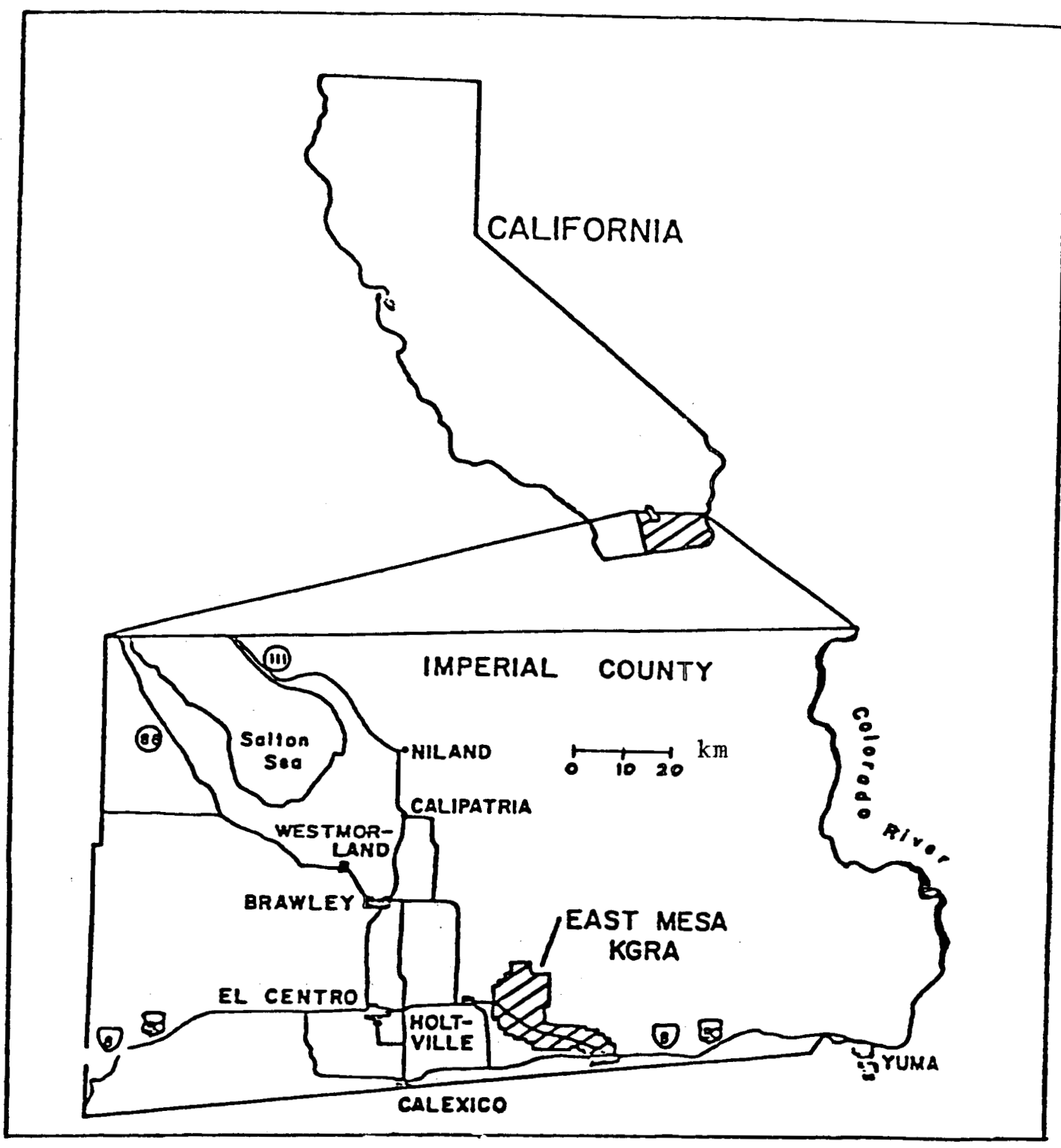

Fig. 13. Location map (from Ref. 12). 


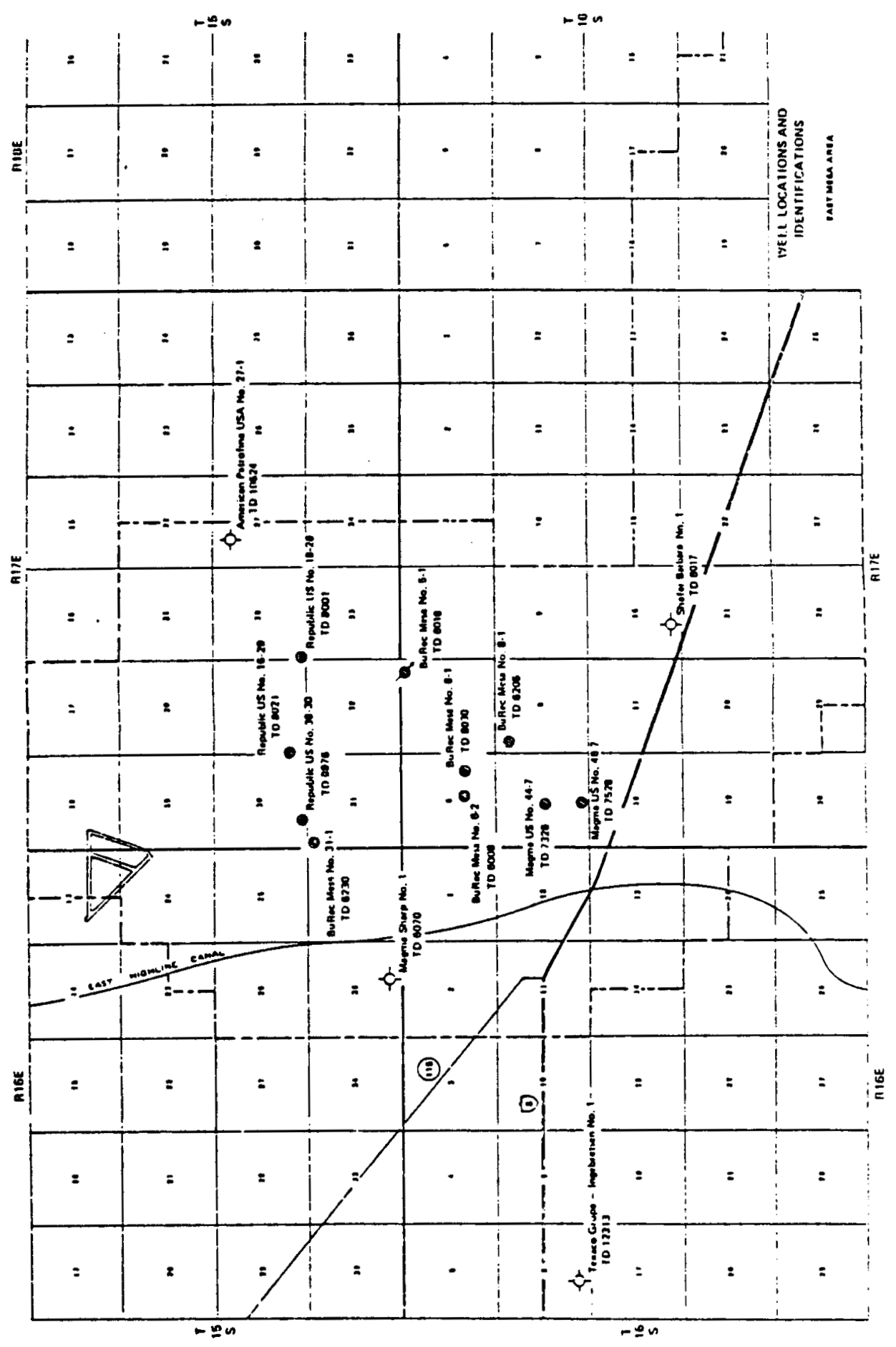

Fig. 14. Well locations as of 1976 (from Ref. 14). 


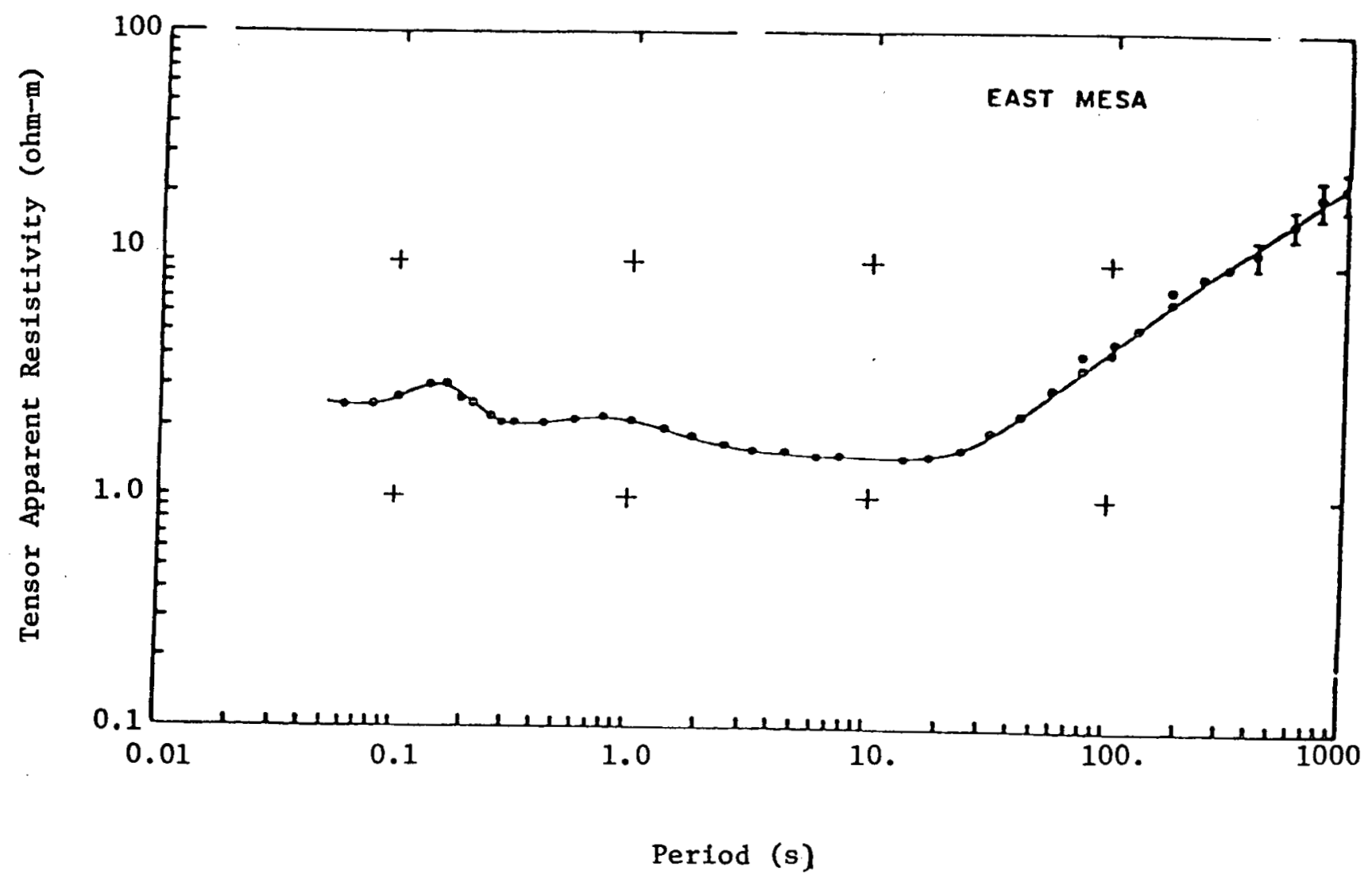

Fig. 15. Magnetotelluric sounding curve obtained at the East Mesa KGRA. 
was utilized for making constrained inversions of the MT data. This code allows one-dimensional inversions to be made with selected layer thicknesses or resistivities in the model constrained to predetermined values. An initial assumed model must be input if any constraints are applied, although totally unconstrained inversions can be made without inputting inital assumptions. Table III shows the results of a free inversion using the MT sounding data alone. Improved results were then sought by utilizing portions of the resistivity $\log$ as constraints on the inversion of the MT sounding.

For use in combination with the MT data, the resistivity $10 \mathrm{~g}$ from Mesa 6-1 was reduced to a model reflecting only the major resistivity trends. This is given in Table IV. The relatively high resistivity zone, Layer 6 , has high permeability and is a zone of interest. The total resistivity variation is rather small however, making resolution of the different layers from the MT data a difficult task. Although Tables III and IV show some degree of agreement in the upper few hundred meters of the formation, it is clear that the surface MT data by themselves render virtually no useful information at the depths that are of interest for resource evaluation.

When the values from Table IV (plus two high resistivity underlying layers, the second extending to infinity in order to fulfill the requirements of the inversion routine) were used as initial values for an inversion of the MT data, the resulting fit to the field data was superior to that which was achieved by the 
TABLE I I I

UNCONSTRAINED INVERSION OF MT DATA

$\begin{array}{ccc}\text { Layer } & \begin{array}{c}\text { Thickness } \\ (\mathrm{m})\end{array} & \frac{\begin{array}{c}\text { Resistivity } \\ \text { (ohm-m) }\end{array}}{1} \\ 2 & 154 & 2.07 \\ 2 & 168 & 3.13 \\ 3 & 121 & 1.57 \\ 4 & 90 & 2.60 \\ 5 & 866 & 1.06 \\ 6 & 16,600 & 17.10 \\ 7 & \infty & 138.00\end{array}$

TABLE IV

RESISTIVITY MODEL DERIVED FROM LOG OF MESA 6-1

\begin{tabular}{|c|c|c|c|c|}
\hline Layer & $\begin{array}{l}\text { Depth } \\
(\mathrm{m})\end{array}$ & $\begin{array}{c}\text { Thickness } \\
\text { (m) }\end{array}$ & $\begin{array}{l}\text { Resistivity } \\
\text { (ohm-m) }\end{array}$ & Characteristics \\
\hline 1 & $0-116$ & 116 & $\begin{array}{c}\text { free } \\
\text { (not logged) }\end{array}$ & upper, low \\
\hline 2 & $116-177$ & 61 & 4.0 & layers \\
\hline 3 & $177-291$ & 114 & 2.2 & \\
\hline 4 & $291-868$ & 577 & 1.6 & $\begin{array}{l}\text { declining } \\
\text { permeability }\end{array}$ \\
\hline 5 & $868-1160$ & 292 & 2.4 & $\begin{array}{l}\text { minimum } \\
\text { permeability }\end{array}$ \\
\hline 6 & $1160-1867$ & 707 & 4.0 & $\begin{array}{l}\text { high permeability } \\
\text { zone, permeability } \\
\text { declines in lower } \\
200 \mathrm{~m}\end{array}$ \\
\hline 7 & $1867-2184$ & 317 & 1.7 & $\begin{array}{l}\text { minimum } \\
\text { permeability }\end{array}$ \\
\hline
\end{tabular}


unconstrained inversion. Table $V$ gives the resistivity model obtained by this means, which is very similar to the resistivity profile obtained from the well $\log$ (Table IV).

The fact that the model drawn from the well log provides a reasonably good fit to the MT data would be of interest in itself to someone engaged in evaluating the area (the East Mesa area has of course been extensively studied, but a hypothetical case can be considered in which only the data from the MT sounding and the one well are available). The agreement implies that the formation as encountered in the well is reasonably representative of the surrounding area. This would clearly be of interest if the well performed successfully. Contrarily, if the well performed poorly, indications of how representative the well was might be considered in decisions regarding further drilling.

Differences between Table IV and Table $\mathrm{V}$ may be interpretable as some indication of differences between general formation characteristics as sensed by the MT sounding and the localized formation characteristics measured from the borehole. Several thousand meters of formation of similar properties to the sediments penetrated by the borehole are revealed to exist below the total depth of the we11. This was not evident from the unconstrained inversion of the MT data alone. Further, the increased thickness for Layer 4 and reduced thickness for Layer 6 suggest that in the mean formation sensed by the MT sounding the production zone is deeper and thinner than revealed by the $\log$ of Mesa 6-1. 


\section{TABLE Y}

\section{INVERSION OF MT DATA USING TABLE IV FOR INITIAL VALUES}

\begin{tabular}{|c|c|c|c|}
\hline Layer & $\begin{array}{l}\text { Depth } \\
\text { (m) } \\
\end{array}$ & $\begin{array}{l}\text { Thickness } \\
\text { (m) }\end{array}$ & $\begin{array}{l}\text { Resistivity } \\
\text { (ohm-m) }\end{array}$ \\
\hline 1 & $0-121$ & 121 & 2.3 \\
\hline 2 & $121-184$ & 63 & 4.0 \\
\hline 3 & $184-302$ & 118 & 2.2 \\
\hline 4 & $302-976$ & 674 & 1.3 \\
\hline 5 & $976-1273$ & 297 & 2.2 \\
\hline 6 & $1273-1948$ & 675 & 3.6 \\
\hline 7 & $1948-2269$ & 321 & 1.7 \\
\hline 8 & $2269-6190$ & 3920 & 6.4 \\
\hline 9 & $6190-\infty$ & -- & 220 \\
\hline
\end{tabular}


The East Mesa area has of course been extensively drilled, and it is possible to refer to other wells and well logs for information. An extensive discussion of the formation is given in the case history of well logging at East Mesa, Ref. 14. Figure 16 displays permeability and porosity profiles computed from density and sonic logs in Mesa 6-1,6-2, and 8-1 (Ref, 13), Mesas 6-2 and 8-1 being the wells closest to 6-1. There is a substantial degree of similarity among the three wells, and distinctive features can be identified, especially from the permeability profiles. Declining permeability above $900 \mathrm{~m}$ and the low permeability zone about $1000 \mathrm{~m}$ may correspond to Layers 4 and 5 in Table $V$. The high-permeability production zone corresponding to Layer 6 with a second minimum permeability layer (Layer 7) below it are also obvious. The comparison of the profiles for all three wells reveals that the high-permeability zone does appear in Mesa 6-1 about $100 \mathrm{~m}$ shallower and substantially thicker than in the other wells, thus corresponding to the conclusions drawn from Table $V$. The inversion of the MT data using the $\log$ data is thus useful in extending knowledge of the formation over a larger lateral area than provided by the well $\log$.

Other types of lateral investigation can also be made if sufficient surface data are available. Lateral changes away from the borehole can be located once a suitable inversion for the vicinity of the borehole has been established. A set of resistivity soundings extending away from the borehole can be inverted, 

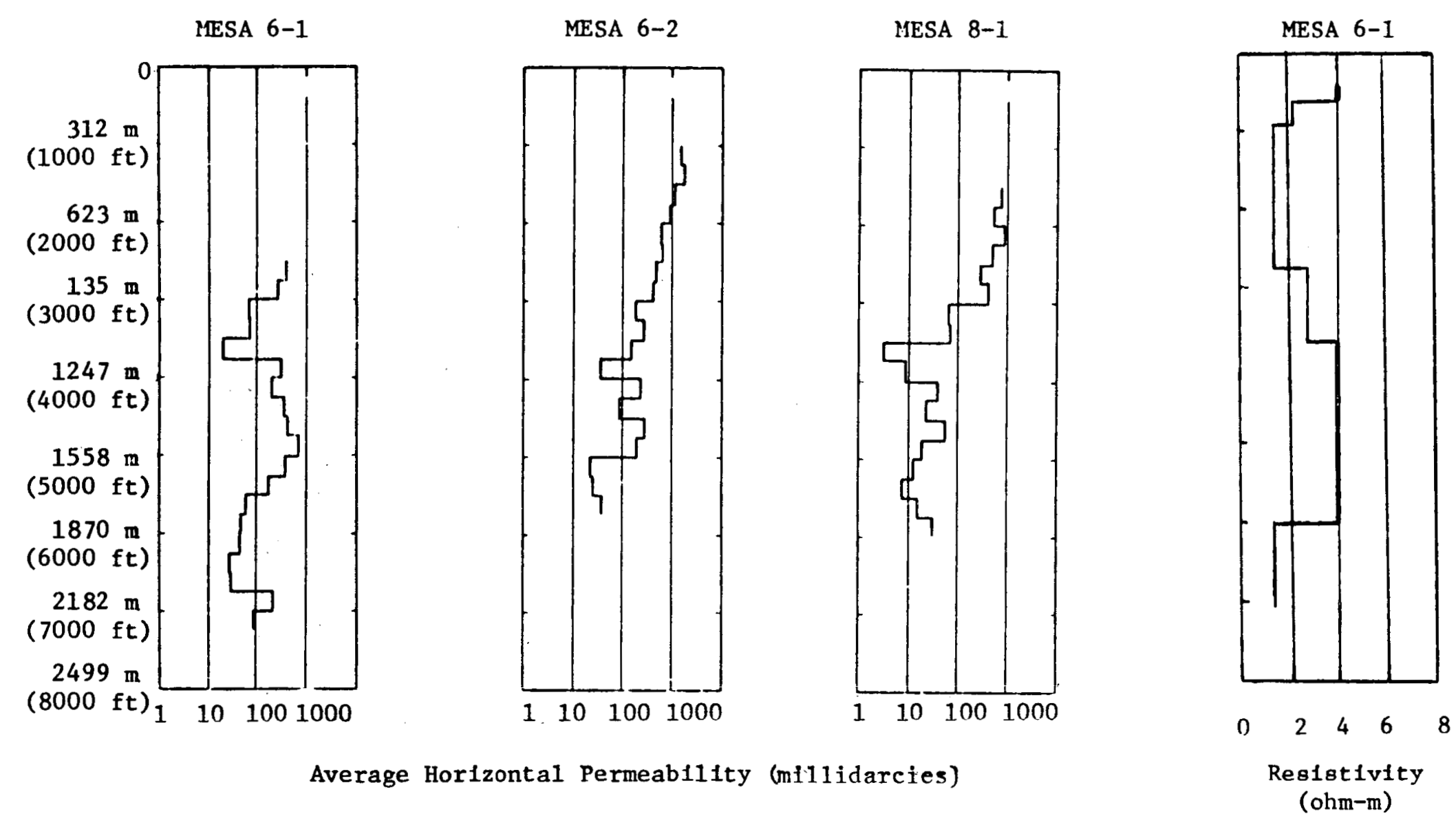

Fig. 16a. Permeability profiles computed for the Bureau of Reclamation we11s (from Ref. 13) and the resistivity profiles for Mesa 6-1 given in Table IV. 


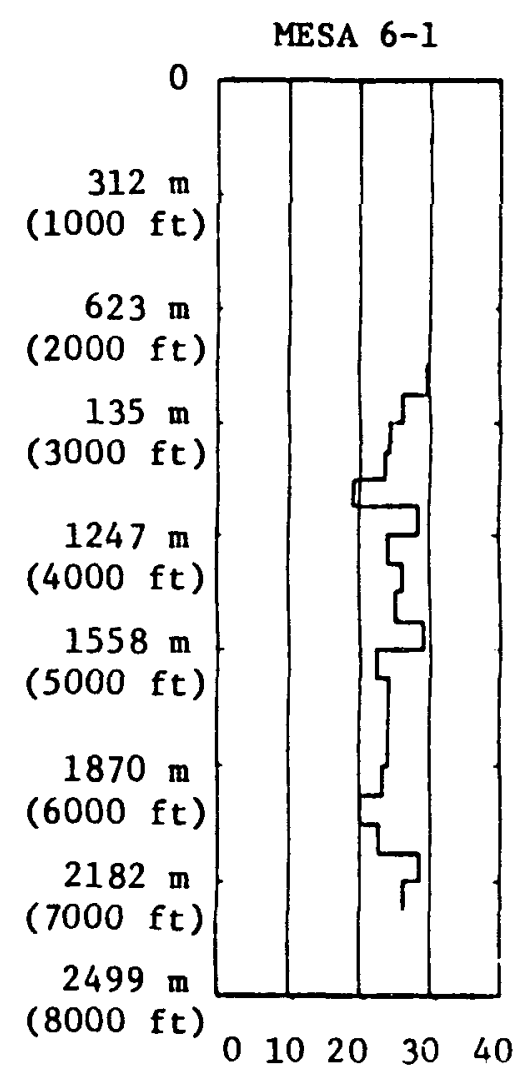

PAESA 6-2

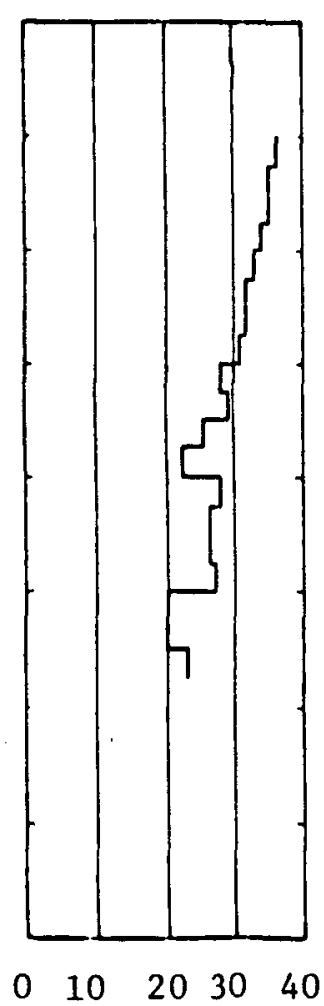

Average Porosity $\left(\frac{0}{\partial}\right)$
IESA 8-1

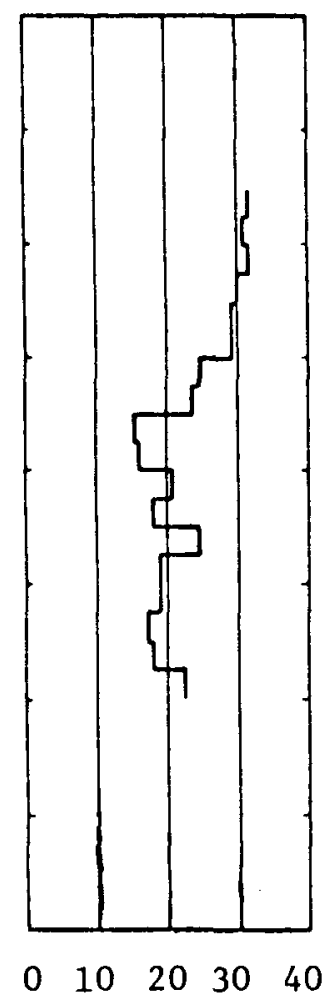

$\begin{array}{lllll}0 & 10 & 20 & 30 & 40\end{array}$

Fig. 16b. Porosity profiles (from density log data) for the Bureau of Reclamation wells (Ref. 13). 
constrained to the same model. If for one set of soundings the model breaks down, then a lateral boundary has been crossed. This kind of lateral extension could not be tested at East Mesa since only one MT sounding was available, but an example exists from an investigation of a damsite.

In work for the Bureau of Reclamation (Ref. 15), the code has been applied to the location of lateral changes in resistivity surveys. In that case, a set of vertical electric soundings with a Schlumberger spread had been made along a line near a proposed damsite. By inverting each sounding with the number of model layers constrained to the same value (4), it was possible to show that along one portion of the line the data fitted a reasonably uniform model. The point at which the sounding data departed radically from the four-layer model could then be identified. Although borehole data for the damsite were available, they were not used in developing the specific constraints applied. Nonetheless, the Bureau of Reclamation's application demonstrates a use of the ability to constrain the inversion of surface survey data. The problem of locating the lateral limits of a formation is relevant to problems of geothermal reservoir evaluation. D. Vertical Extrapolation

A second application that was attempted was use of the MT sounding to make a downward extrapolation of the resistivity mode 1 obtained from the well $\log$. The MT data were inverted, constrained to 9- and 10-1ayer mode1s with the first five layers matching Table IV to reflect the information that would be available if the well 
were on $1 y$ deep enough to penetrate partially into the sixth layer, about a depth of $1400 \mathrm{~m}$ (resistivity of the first layer was left free since this section was not logged). A thickness of $300 \mathrm{~m}$ and a resistivity of $3.4 \mathrm{ohm}-\mathrm{m}$ were used as initial conditions for Layer 6 (the well $10 \mathrm{~g}$ indicated that resistivity was less than $4 \mathrm{ohm}-\mathrm{m}$ in the upper part of Layer 6 and greater in the lower part). Since the unconstrained inversion shows only high resistivities below this level, the unconstrained layers below the sixth were assumed to have thicknesses and resistivities increasing with depth as an initial assumption for the inversion routine. Values of the lower four layers resulting from this constrained inversion of the MT data are given in TableVI (the first five layers were constrained to correspond to Table IV). Figure 17 shows the fit to the MT data.

Although the resolution of the inversion at these depths is very limited, given the small resistivity contrasts, the constrained inversion does accurately extrapolate the presence of the low resistivity of Layer 7 and gives a value for the thickness of Layer 6 that is not unreasonable in terms of the permeability profiles in Fig. 17

TABLE VI

RESULTS OF VERTICAL EXTRAPOLATION USING FIRST FIVE LAYERS FROM TABLE III AS CONSTRAINTS ON THE INVERSION OF THE MT DATA

\begin{tabular}{|c|c|c|c|}
\hline Layer & $\begin{array}{l}\text { Depth } \\
\text { (m) }\end{array}$ & $\begin{array}{l}\text { Thickness } \\
\text { (m) }\end{array}$ & $\begin{array}{c}\text { Resistivity } \\
(0 h m-m)\end{array}$ \\
\hline 6 & $1160-1503$ & 343 & 3.4 \\
\hline 7 & $1503-2117$ & 614 & 1.6 \\
\hline 8 & $2117-3840$ & 1720 & 3.3 \\
\hline 9 & $3840-\infty$ & -- & 107 \\
\hline
\end{tabular}




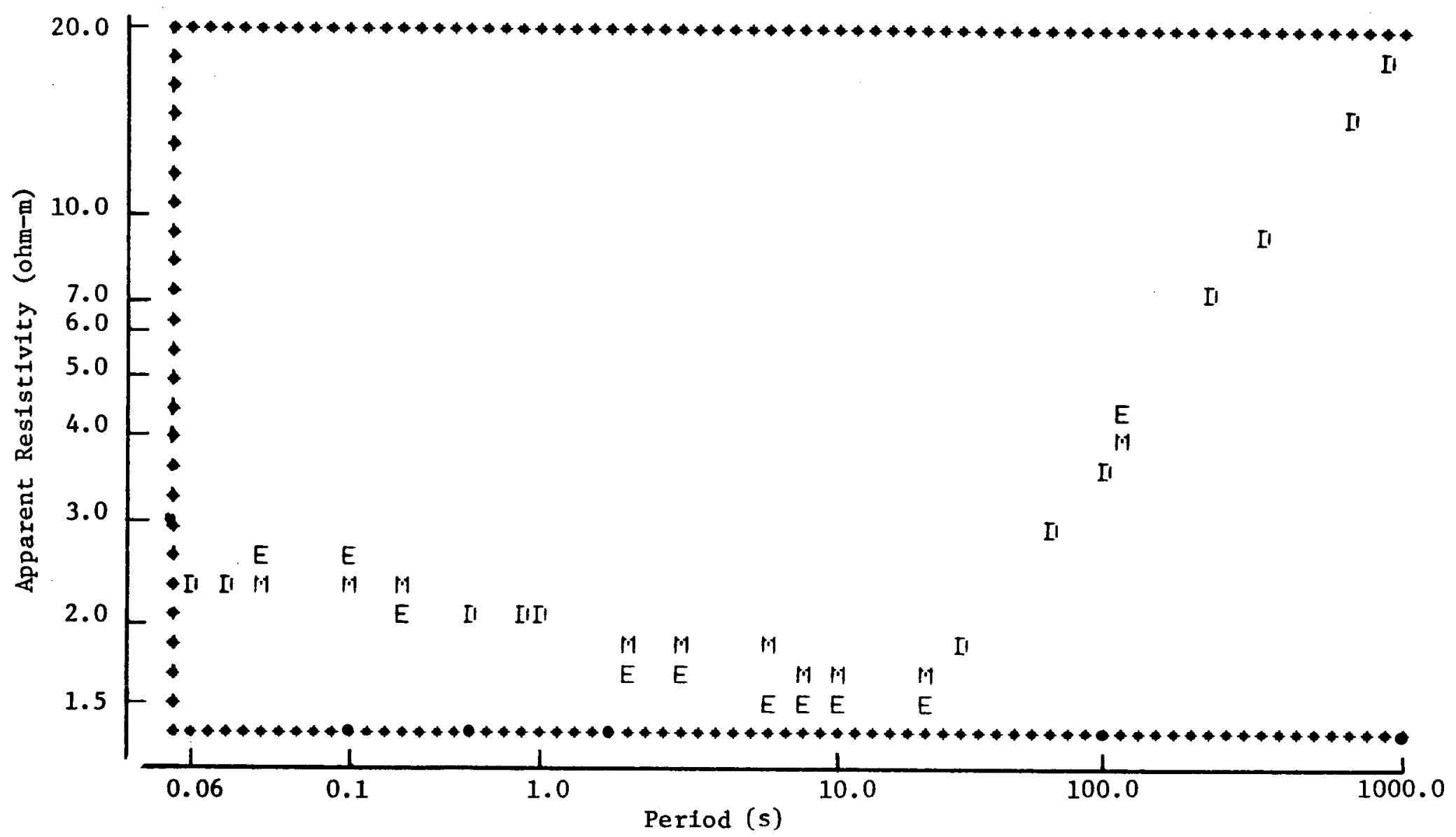

Fig. 17. Plot of fit between measured data (E) and apparent resistivities calculated from the model in Table $V$ (with the first five layers identical to Table IV) shown by $M$. D represents coincident points. 
E. Conclusions

Inversion of surface resistivity data using constraints drawn from resistivity logs in nearby wells produced results for the East Mesa example that indicated reservoir features that could not be found from either data set alone. The possibility of improved estimation of reservoir geometry, including thickness, position, and lateral extent of producing zones, was found. The possibility of extrapolating the well log vertically was also found to exist. The sensitivity for vertical extrapolation was much better for lowresistivity zones than for high resistivity. Estimates arrived at in the benefit/cost study (Ref. 1) indicating that the combination of accurate $\log$ data from geothermal wells with surface geophysical data could provide information leading to improved drilling success and better resource evaluation appears to be supported. However, the review of geophysical survey data available for several geothermal areas showed that at many areas the geophysical studies made did not have sufficient detail to be of much value for developing subsurface models. Efforts are needed to introduce the geothermal industry and federally supported programs to the value of combining well $\log$ data and surface geophysics. 
IV . BENEFITS ATTRIBUTABLE TO IMPROVED LOGGING DATA

Rigby and Reardon 1 analyzed the potential benefits that may be realized as a result of the increased knowledge of the resource that may be obtained through improved logging and $\log$ interpretation in geothermal we11s. Major benefits were judged to be possible in several aspects of geothermal drilling and development. Benefits related to drilling and field development were related to factors that could reduce costs and included improved drilling success, reduced flow testing, reduced well costs in drilling and completion and reduced expenses for reinjection. In addition, it is possible that better reservoir information may result in an acceleration of plant development and earlier achievement of poweron-1ine.

The applications of well $10 \mathrm{~g}$ data examined in the foregoing sections of this report bear on some of these benefits and on the priorities that may be reasonable for research in improving geothermal well $10 \mathrm{~g}$ interpretation. Furthermore, in the past two years, inflation, the pace of geothermal development, and the rising price of oil may have changed the benefit totals for the study. The results of the cost/benefit analysis therefore require updating.

\section{A. Review of Benefit/Cost Analysis for Research in Geothermal Log Interpretation}

The quantitative analysis of benefits from improved geothermal we11 $10 \mathrm{~g}$ data was based on development of geothermal energy for electric power generation only. Development of geothermal resources for direct use can also be a potent source of growth in the 
United States' domestic energy picture, but the impact of logging data in this area is less clear. Exploration and development patterns are not yet well enough established to allow projections of the use that may be made of well $10 \mathrm{~g}$ information in direct use applications. Thus, the quantitative benefit analysis is limited to development for generation of electricity by necessity rather than because benefits from improved geothermal $10 \mathrm{~g}$ interpretation will be limited to this aspect of geothermal energy utilization. Similarly, consideration is limited to the conventional hydrothermal resources, excluding the geopressured geothermal resources of the Gulf Coast and the possibility of development of hot dry rock resources. It must rest with the reader to keep in mind that quantified cost/benefit estimates for research in improving geothermal $\log$ interpretation based on near-term hydrothermal development for power generation can only be a guide to total benefits and are not all-embracing.

For the cost/benefit analysis in Ref. 1, use was made of a development scenario developed by the MITRE Corporation for the Department of Energy. Table VII summarizes this power-on-1ine scenario. Drilling activity and cost scenarios developed for this scenario can be found in Refs. 1 and 16. Benefits from improved geothermal log data were interpreted as taking the form either of reduced field development costs or accelerated achievement of 
power-on-1ine. The undiscounted benefit totals estimated in 1979 were: ${ }^{1}$

- improved drilling success rate, $\$ 142.5 \times 10^{6}$,

- reduced costs for unsuccessful exploratory wells, $\$ 40.1 \times 10^{6}$,

- reduced flow testing time, $\$ 63.6 \times 10^{6}$,

- reduced well costs, $\$ 142.5 \times 10^{6}$,

- reduced costs for reinjection, $\$ 65.1 \times 10^{6}$, and

- accelerated power-on-1ine, $\$ 117.0 \times 10^{6}$.

To update these, inflation, the rate of geothermal development, and changes in the cost of energy need to be accounted for.

It is beyond the scope of the present work to develop a new scenario for geothermal development in the United States. The development scenario of Table VII must remain the basis for cost/ benefit estimates, but it is reasonable to review the adequacy of that scenario for the more advanced resource sites.

Inevitably, the pace of geothermal development in the past few years has not perfectly matched the scenario. Delays in the realization of federal initiatives to encourage geothermal development, changing environmental and regulatory concerns, and high interest rates can slow development compared to earlier expectations; on the other hand, the constantly rising price of energy represents an increasing impetus to development, and state and local efforts are being made in some areas to clear away barriers to geothermal development. Increased knowledge of the resource from new exploration data can change the picture at individual resource areas either 
POWER ON-LINE SCENARIO (MW) USED IN REF. 1

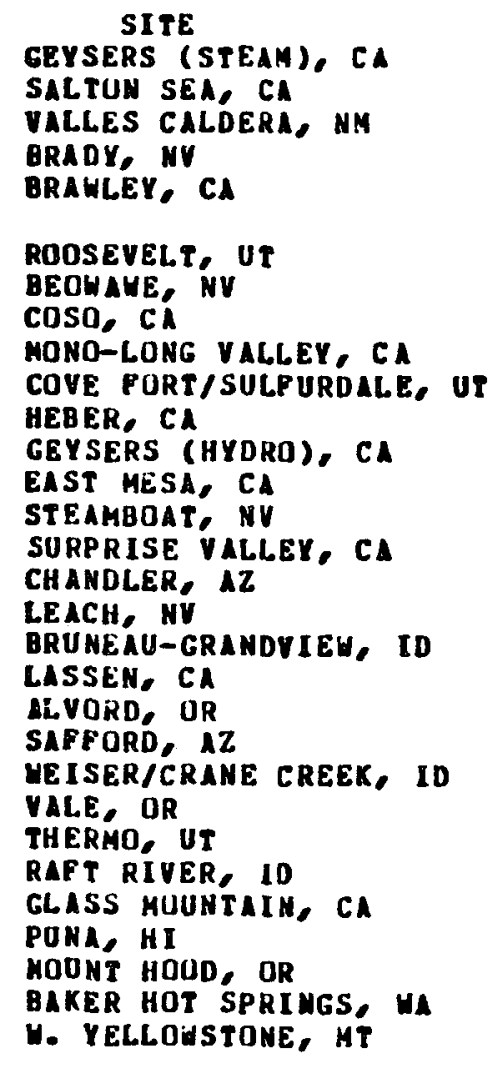

rotals

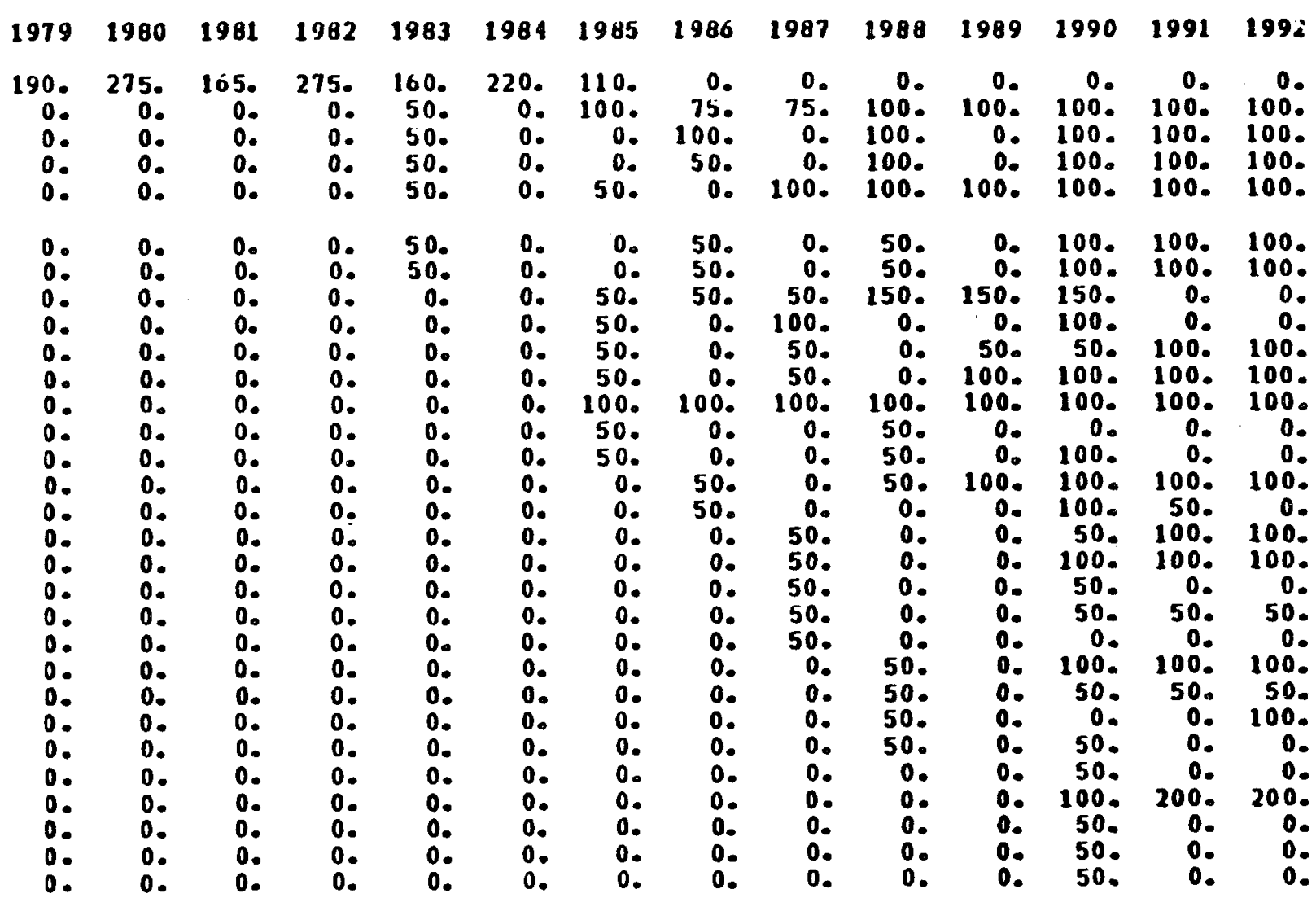

190. 275. 165. 275. 460. 220.660. 575. 775. 1100.700. 2150. 1650.1700. 
way. Curiously; rising oil prices and deregulation can also have a mixed impact on the geothermal industry, because the impact on energy prices encourages geothermal development, while increased oil exploration can draw needed equipment and investment capital away from geothermal prospects in the short term. At the Geysers' steam field, the scenario projects a development rate that would have brought total capacity to nearly $1000 \mathrm{MW}$ by the end of 1980. However, solving environmental difficulties led to delays and at present, in the latter half of 1980 , capacity at the Geysers is about $800 \mathrm{MW}$ with several new plants due to come on-line soon. At the Salton Sea, a 28 -MW power plant may be online in 1982, and another plant of $50 \mathrm{MW}$ may be built in 1984 , representing some acceleration of the scenario. At the Valles Caldera, Department of Energy funding for the demonstration plant holds promise of $50 \mathrm{MW}$ on-1ine in 1983 or 1984. At Brady, Nevada, poor exploration results suggest that power generation may not begin for some time. However, it is also true that recent exploration in Nevada has revealed new resource prospects such as Dixie Valley that may well hold promise for development in the late $1980 \mathrm{~s}$. At Brawley a $10-\mathrm{MW}$ facility is already in operation and additional power plants may be expected in a few years. At Roosevelt Hot Springs, limited local demand makes development slower than the original scenario, but a $20-\mathrm{MW}$ plant will be begun soon. At Beowawe an estimate of 1983 for a 50-MW power plant appears rather optimistic; but resource companies are seeking a utility customer, 
and rapid development is a reasonable prospect. The Navy is encouraging development at Coso Hot Springs. The Mono-Long Valley and Cove Fort-Sulfurdale prospects, however, have received less attention of late. On the other hand, the demonstration project at Heber may put a 50-MW plant on-line in 1984 , a year ahead of the scenario. Interest is also high in the waterdominated resource at the Geysers. A 10-MW power plant is operating at East Mesa and additional capacity may come on-1ine in the early 1980s. Encouraging exploration drilling results have been achieved at Steamboat Springs. As these comments make clear, the pace of development is keeping up with (or even leading) the original scenario in a few areas and running somewhat behind the scenario in a number of others. Not surprisingly, the areas where drilling costs are high are also those which are behind the scenario. Since these are also the areas where the benefits of improved well $\log$ data are greatest, it was decided to assume that the scenario had slipped by one year in updating the cost/benefit results. The original cost/benefit analysis was performed in terms of 1979 dollars. In order to convert this to 1981 dollars, a total inflation rate of $25 \%$ was assumed for the two years, 1979 and 1980. This estimate is conservative in view of the fact that the final cost-of-1iving figures for 1979 indicated $13.3 \%$ inflation for the year, and in 1980 inflation has been near $12 \%$. Further implicit in the use of the inflation rate is the assumption that drilling costs will increase at a rate commensurate with other prices, when in fact the present high level of drilling in the United States has tended to drive costs up more rapidly. 
The estimate of the value of accelerated achievement of power-on-line is based on the displacement of oil. Although the benefit from accelerated power-on-line to the developer is equal to the full value of the extra electricity generated (less costs of operation), the analysis of benefits for government research should be based on national impacts. The benefit of earlier geothermal power-on-line was therefore taken to be equal to the cost of oil required to generate an equal amount of electricity. The value of the oil was taken to be the price for imported oil. In the original study a price of $\$ 16 / b b 1$ was used. The price of Saudi Arabian oil is now $\$ 30 / \mathrm{bb} 1$ and seems liable to increase before the end of 1980. To convert to 1981 values, therefore, the benefits from accelerated achievement of power-on-1ine were assumed to have doub1ed (oil at $\$ 32 / \mathrm{bb} 1$ ), rather than to have increased at the rate of inflation.

Table VIII shows the updated benefit and cost estimates. As in Ref. 1 the benefit computation is based on an assumed eightyear period of improvement in geothermal logging and interpretation. The net total estimate of benefits potentially available from improved geothermal well log data (which requires both improved interpretation techniques and tool improvements to allow logging of high temperature wells) is $\$ 746$ million in undiscounted value through 1993 in 1981 dollars. Discounted present value for $5 \%$ and $10 \%$ discount rates are also included. 
TABLE VIII

UPDATED ESTIMATES FOR BENEFIT/COST ANALYSIS

(IN MILLIONS OF 1981 DOLLARS)

\begin{tabular}{|c|c|c|c|c|c|c|}
\hline Year & $\begin{array}{l}\text { Benefits } \\
\text { Field- } \\
\text { Related } \\
\end{array}$ & $\begin{array}{l}\text { Earlier } \\
\text { Power- } \\
\text { On-Line } \\
\end{array}$ & $\begin{array}{l}\text { Logging } \\
\text { Cost }\end{array}$ & Total & $\begin{array}{c}5 \% \\
\text { Annual } \\
\text { Discount } \\
\end{array}$ & $\begin{array}{c}10 \% \\
\text { Annual } \\
\text { Discount }\end{array}$ \\
\hline 1981 & 2.8 & 0 & 3.8 & -1.0 & -1.0 & -1.0 \\
\hline 1982 & 6.0 & 0 & 4.2 & 1.8 & 1.7 & 1.6 \\
\hline 1983 & 10.0 & 0 & 4.6 & 5.4 & 4.9 & 4.5 \\
\hline 1984 & 16.7 & 5.0 & 7.0 & 14.7 & 12.7 & 11.0 \\
\hline 1985 & 20.0 & 0 & 7.2 & 12.8 & 10.5 & 8.7 \\
\hline 1986 & 44.4 & 18.2 & 10.2 & 52.4 & 41.4 & 32.5 \\
\hline 1987 & 59.9 & 16.6 & 16.2 & 60.3 & 45.0 & 34.0 \\
\hline 1988 & 42.5 & 28.8 & 11.2 & 60.1 & 42.7 & 30.8 \\
\hline 1989 & 138.9 & 35.0 & 30.4 & 143.5 & 97.1 & 66.9 \\
\hline 1990 & 105.1 & 24.2 & 22.4 & 106.9 & 68.9 & 45.3 \\
\hline 1991 & 113.4 & 80.2 & 25.5 & 168.1 & 103.2 & 64.8 \\
\hline 1992 & - & 59.0 & - & 59.0 & 34.5 & 20.7 \\
\hline 1993 & - & 66.6 & - & 61.6 & 34.3 & 19.6 \\
\hline TOTAL & 559.7 & 328.6 & 142.7 & 745.6 & 495.6 & 339.4 \\
\hline
\end{tabular}


Undiscounted benefit totals for the various categories related to field development are:

- improved drilling success - $\$ 175.8 \times 10^{6}$,

- reduced exploratory drilling - $\$ 49.5 \times 10^{6}$,

- reduced flow testing - $\$ 78.4 \times 10^{6}$,

- reduced drilling costs - $\$ 175.8 \times 10^{6}$, and

- reduced reinjection requirements - $\$ 80.3 \times 10^{6}$.

\section{B. Impact on Data Priorities}

The investigations reported in Sections II and III of this report are related to the assumption of potential benefits in flow testing and well siting (improved success rate). The results reported provide validation for the assumptions that there are data needs for geothermal well test evaluation that can be met by development of new $10 \mathrm{~g}$ interpretation techniques and that $10 \mathrm{~g}$ data can interact with other geophysical data in ways that may be useful in developing a model of the reservoir and in well siting. Better reservoir data also contribute to the confidence with which reservoir performance is predicted and thus to the more rapid achievement of power-on-1ine.

Earlier power-on-line is by far the largest single source of benefits. Although the sum of potential cost reductions in field development exceeds the estimated benefit from earlier power-online, the rapid increase in oil prices has greatly increased the relative value of scenario acceleration compared to the 1979 estimates. Furthermore, as long as the cost of energy (and especially the value of adding to domestic energy supplies) continues 
to rise more rapidly than other prices, there will be a continued increase in the dominance of this benefit category.

The changed relative magnitude of some of the benefit categories and the applications of $10 \mathrm{~g}$ data examined in the first sections of this report have an impact on the priorities of research in $10 \mathrm{~g}$ interpretation. The greatly increased magnitude of the benefits associated with resource evaluation and earlier commitment to development (earlier power-on-line) implies that an increased emphasis is appropriate for $10 \mathrm{~g}$ data that are important for this decision. For example, while porosity does not hold the significance it does for hydrocarbon exploration, the discussion in Section II has shown that knowing bulk fracture properties such as the partition of porosity between fractures and disseminated matrix porosity may be very useful in testing and evaluating dual porosity reservoirs. Identification of zones with high fracture porosity can also assist in identifying the producing intervals. In contrast, discrete fracture characteristics such as location and orientation have impacts primarily on controllingdevelopment costs, and may have a lesser priority.

Thermal characteristics provide another example. Accurate determination of reservoir temperature remains essential, of course, and the importance of achieving reliable and consistent temperature logging is unchanged. On the other hand, efforts have also been made to develop means to get a quick measurement or estimate of undisturbed formation temperature. This estimate 
may yield savings of time and expense in exploration and field development. These benefits are significant, but may not contribute strongly to long-term resource assessment and modeling; some revision of relative priorities may be appropriate.

Accurate 1 ithologic analysis from $10 \mathrm{~g}$ data, on the other hand, has applications in achieving reductions in field costs and is also important for interwe11 correlation, establishing producing interval thickness and accurate evaluation of other $10 \mathrm{~g}$ information. Thus, it remains a high priority. Analysis of fluid characteristics, especially formation fluid salinity, is another interpretation step that can be valuable in deriving other $10 \mathrm{~g}$ parameters and in contributing directly to understanding the hydrologic regime of a resource. Benefits from accurate determination of formation fluid characteristics may be realized in field development and reinjection and in reservoir modeling.

Finally, in Section III an example has been given of the potential applications that may be possible for combined use of borehole logging data and geophysical data taken at the surface. This application is not directly comparable to $10 \mathrm{~g}$ interpretation problems that concern determination of a specific formation parameter. It is clear, however, that such techniques may be useful in well siting, exploration, and resource assessment, thereby contributing to benefit categories that provide over $60 \%$ of the benefit total. Realization of these benefits depends on the development of appropriate interpretation techniques, applied to data sets of use in defining geothermal reservoirs, and also on the decision of the developer to acquire adequate data both at the surface and in the borehole. 
The establishment of research priorities must, of course, depend on a variety of factors including probability of successful research, desires of the target industry, probability of application of techniques developed, and cost and benefit considerations. Factors discussed in this report do not cover the full range of applications of $10 \mathrm{~g}$ data or problems of interpretation, but rather direct attention at certain $10 \mathrm{~g}$ interpretation problems that have evident impacts on the benefit analysis.

\section{Conclusions}

The rapid rise in fossil fuel prices in the past few years has produced an equivalent increase in the value of geothermal energy and makes rapid development of this domestic energy resource all the more desirable. Following upon the rise in energy prices and the success achieved by geothermal projects that are now operating, there has been a rapid expansion in exploration for geothermal resources, and utilities and consumers of space and process heat are displaying increasing interest in geothermal energy. Increasing geothermal exploration and development produces a high demand for borehole logging and formation evaluation, and the expansion of exploration into increasingly complex geologic environments is confronting the log analyst with ever more difficult interpretation problems. The national benefits that can follow from research to solve these logging problems become steadily greater as the value of new domestic energy production rises. The present study has 
reviewed the impact of rising costs on benefits estimated for such research and has considered the value of $10 \mathrm{~g}$ data for certain applications that could not be fully assessed earlier. Significant findings are summarized in Table IX.

\section{TABLE IX}

\section{CONCLUSIONS}

- Net undiscounted benefits from improved geothermal logging and $\log$ interpretation can be conservatively estimated to be on the order of three-quarters of a billion dollars over the next decade.

- While large benefits are possible in reduced field costs, early and more reliable resource evaluation and modeling are a dominant benefit area due to the high value of achieving earlier resource development.

- In many fractured formations, the ability to evaluate bulk fracture properties from logs, especially fracture porosity, can be of significant value in well test analysis (and hence in formation evaluation).

- Combined analysis of log data with surface geophysical data presents striking potential for extending the scope of conventional $10 \mathrm{~g}$ analysis in exploration, well siting, and assessment without specialized borehole-to-borehole or borehole-to-surface techniques. 


\section{REFERENCES}

1. F.A. Rigby and P. Reardon, "Benefit/Cost Analysis for Research in Geothermal Log Interpretation," Los Alamos National Laboratory report LA-7922-MS (July 1979).

2. S.K. Sanya1, L.E. We11s, and R.E. Bickham, "Geothermal Well Log Interpretation State-of-the-Art," Los Alamos National Laboratory report LA-8211-MS (January 1980).

3. A. deSwaan, "Analytic Solutions for Determining Naturally Fractured, Reservoir Properties by We11 Testing," Society of Petroleum Engineers Journa1, 117-122 (June 1976).

4. J.E. Warren and P.J. Root, "The Behavior of Naturally Fractured Reservoirs," Society of Petroleum Engineers Journal, 245-255 (September 1963).

5. H. Kazemi, "Pressure Transient Analysis of Naturally Fractured Reservoirs with Uniform Fracture Distribution," Society of Petroleum Engineers Journa1, 451-462 (December 1969).

6. G.F. Pinder, "State-of-the-Art Review of Geothermal Reservoir Modeling," Geothermal Subsidence Research Management Program, Lawrence Berkeley Laboratory, University of California, report LBL9093, GSRMP-5 (March 1979).

7. A.T. Corey, C.J. Rathjens, J.H. Henderson, and K.J. Wylie, "Three-Phase Relative Permeability," Transactions of the AIME, 207, p. 49 (1956).

8. H.D. Murphy, "Hot Dry Rock Geothermal Heat Extraction Experiments," in Expanding the Geothermal Frontier, Geothermal Resources Council Transactions, 3, 473-476 (September 1979).

9. D.G. Stoone and H.B. Evans, "Extrapolating Logs Run in Exploration or Development Wells Using Seismic Data," Society of Professional Wel1 Log Analysts, Twenty-First Annual Logging Symposium, Proceedings, paper KK (July 8-11, 1980).

10. J. Combs, "Geothermal Exploration Techniques: A Case Study," Electric Power Research Institute report EPRI ER-680, Project 375 (February 1978).

11. T. Meidav, personal communication (1979).

12. J.R. Hoaglund, "Petrology and Geochemistry of Hydrothermal Alteration in Borehole Mesa 6-2, East Mesa Geothermal Area, Imperial Valley, California," IGPP report IGPP-UCR-76-12 (1976). 


\section{REFERENCES (Continued)}

13. TRW Systems Group, "Study of the Geotherma1 Reservoir Underlying the East Mesa Area, Imperial Valley, California," U.S. Bureau of Reclamation report 28859-6001-RU-00, 1 and 2 (1976).

14. D.G. Davis and S.K. Sanyal, "Case History Report on East Mesa and Cerro Prieto Geothermal Fields," Los Alamos National Laboratory report LA-7889-MS (June 1979).

15. R.B. McEuen, "CRIMPA Analysis of Brantley Damsite Resistivity Data," available from the Water and Power Resources Service, Bureau of Reclamation, Denver, Colorado (1979).

16. MITRE Corporation, "Prospects for Improvement in Geothermal We11 Technology and Their Expected Benefits," U.S. Department of Energy, HCP/T4014-04 (June 1979). 


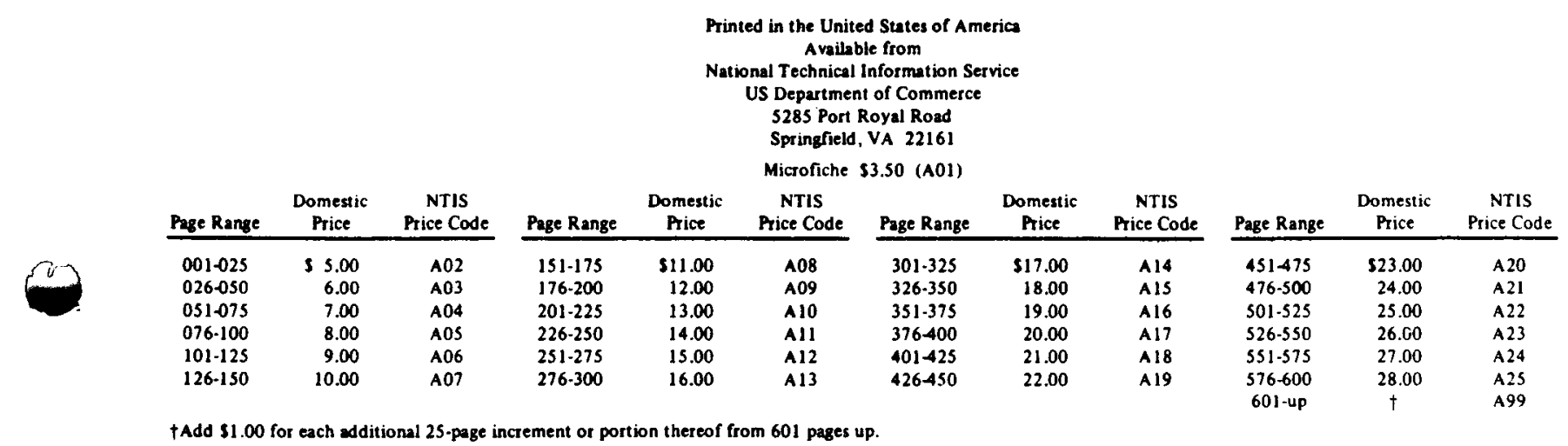

